\title{
Failure Mode Analysis of V-Shaped Pyrotechnically Actuated Valves
}

\author{
Jai S. Sachdev ${ }^{1}$,A. Hosangadi ${ }^{2}$, \\ Combustion Research and Flow Technology Inc., 6210 Keller's Church Rd., Pipersville, PA, 18947 \\ James D. Chenoweth ${ }^{3}$, \\ Combustion Research and Flow Technology Inc., 7501 S. Memorial Parkway Ste. 200, Huntsville, AL, 35802 \\ and \\ Regor L. Saulsberry ${ }^{4}$, and Stephen H. McDougle ${ }^{5}$ \\ NASA Johnson Space Center White Sands Test Facility, Las Cruces, NM, 88004
}

\begin{abstract}
Current V-shaped stainless steel pyrovalve initiators have rectified many of the deficiencies of the heritage $Y$-shaped aluminum design. However, a credible failure mode still exists for dual simultaneous initiator (NSI) firings in which low temperatures were detected at the booster cap and less consistent ignition was observed than when a single initiator was fired. In order to asses this issue, a numerical framework has been developed for predicting the flow through pyrotechnically actuated valves. This framework includes a fully coupled solution of the gas-phase equation with a non-equilibrium dispersed phase for solid particles as well as the capability to model conjugate gradient heat transfer to the booster cap. Through a hierarchy of increasingly complex simulations, a hypothesis for the failure mode of the nearly simultaneous dual NSI firings has been proven. The simulations indicate that the failure mode for simultaneous dual NSI firings may be caused by flow interactions between the flame channels. The shock waves from each initiator interact in the booster cavity resulting in a high pressure that prevents the gas and particulate velocity from rising in the booster cap region. This impedes the bulk of the particulate phase from impacting the booster cap and reduces the heat transfer to the booster cap since the particles do not impact it. Heat transfer calculations to the solid metal indicate that gas-phase convective heat transfer may not be adequate by itself and that energy transfer from the particulate phase may be crucial for the booster cap burn through.
\end{abstract}

\section{Introduction}

$\mathrm{P}$ rotechnically actuated valves (or pyrovalves) are used for critical safety functions in almost all liquid and solid rocket systems. Consequently, pyrovalves must be extremely reliable with $99 \%$ reliability and $90 \%$ confidence interval level. The pyrotechnic energy for actuation in these valves comes from a titanium hydride potassium perchlorate (THPP) booster that is part of the firing train contained by the Primer Chamber Assembly (PCA). An initiator ignites the booster through small "flame channels" in the PCA. Reliable and safe operation of the initiator is essential to ignite the booster and this is strongly dependent on the design features of the flame channels, its material properties, as well as the initiator firing sequence.

\footnotetext{
${ }^{1}$ Research Scientist, 6210 Keller's Church Rd., Pipesville, PA, 18947, AIAA Member

${ }^{2}$ Principal Research Scientist, 6210 Keller's Church Rd., Pipesville, PA, 18947, AIAA Senior Member

${ }^{3}$ Research Scientist, 7501 S. Memorial Parkway Ste. 200, Hunstville, AL, 35802, AIAA Member

${ }^{4}$ Project Manager, Laboratories Office/RF, P.O. Box 20, Las Cruces, New Mexico 88004, AIAA Senior Member

${ }^{5}$ Senior Project Engineer, Laboratories Department/201LD, P.O. Box 20, Las Cruces, New Mexico 88004, AIAA Associate Fellow
} 
Two different designs of PCA are available; a heritage Aluminum (AL) design with a "Y" shaped flow path and a modified stainless steel (SS) configuration with a "V" shaped flow path where both legs of the flame channel independently impinge on the booster. ${ }^{1}$ The stainless steel configuration came about following a study conducted by the NASA Engineering \& Safety Center (NESC) in 2008 of four spacecraft pyrovalve anomalies that occurred during ground testing. In all four cases, a common aluminum ( $\mathrm{Al}$ ) primer chamber assembly (PCA) was used with dual NASA Standard Initiators (NSIs). In all four cases, the nearly simultaneous (separated by less than 80 microseconds $(\mu \mathrm{s})$ ) firing of both initiators failed to ignite the booster charge. ${ }^{2}$

As a result of the four Al PCA anomalies, and the test results and findings of the NESC assessment, the Mars Science Laboratory (MSL) project team decided to make changes to the PCA. The material for the PCA body was changed from aluminum (Al) to stainless steel (SS) to avoid melting, distortion, and potential leakage of the NSI flow passages when the device functioned. The flow passages, which were interconnected in a Y-shaped configuration (Y-PCA) in the original design, were changed to a V-shaped configuration (V-PCA). The V-shape transferred energy more efficiently from the NSIs to the booster. Development and qualification testing of the new design clearly demonstrated faster booster ignition times compared to the legacy AL Y-PCA design. However, while the modified SS design rectified many of the deficiencies of the heritage AL design, further testing was performed to better quantify the performance improvements and investigate credible failure modes. ${ }^{3}$

It must be noted that the AL Y-PCA has demonstrated the ability to consistently ignite a booster with a single NSI firing, or when the firing skew is greater than $2 \mathrm{~ms}$, both in practice and in these recent investigations. The SS V-PCA units avoid flame passage melting and erosion, energy loss, and potential leakage of the NSI flow products. Testing performed in 2011 and documented in NESC \# NESC-RP-0900596 showed that the V-PCA units produced an average maximum booster/propellant interface temperature approximately $600{ }^{\circ} \mathrm{F}$ greater than that delivered by the Al Y-PCA units. The higher temperatures delivered to the booster interface provides added assurance of booster propellant ignition. Further, the higher temperatures with the SS V-PCAs were achieved in approximately half the time; 776 $\mu$ s average for the SS V-PCAs versus 1,342 $\mu$ s average for the Al Y-PCAs. This has resulted in faster ignition of the booster as demonstrated in other related testing. The SS V-PCA units produced pressures in the NSI cavity that were approximately 3,000 psi greater than the Al Y-PCA units. However, the testing also showed that dual, simultaneous (within $20 \mu \mathrm{s}$ ) firing of the redundant NSIs significantly reduces the performance of either PCA design to the point where it is doubtful the booster charge would be reliably ignited. Thus, credible failure modes still remain for dual simultaneous initiator (NSI) firings.

This is counterintuitive since we would normally expect higher energy from dual firings as compared to a single NSI firing. Despite the nearly simultaneous firing of the dual initiators the temperature at the booster covers were very low and in some cases below the detection limit. In contrast, single firings of the initiator provided large temperatures and consistent ignition times particularly in the SS design. Thus it is appears that the unsteady gas-dynamic interactions between each leg of the flame channel play a critical role in the optimal operation of the PCA. This test data provides a good basis for a detailed fluid dynamic (computational) analysis.

The objective under the current effort is to provide insight into this failure mode through a detailed fluid dynamic analysis of the single and simultaneous dual firings. This work will focus solely on the SS design. Since the emphasis is on the gas-dynamic interactions between each flame channel as the cause of the failure, simplifications have been made to allow for a quicker and more efficient preliminary investigation. Specifically, the heat transfer to the solid walls was neglected and an inviscid gas was assumed. Furthermore, afterburning or combustion of the particulate phase was also neglected. Initial calculations were performed on a 2-D planar configuration to allow rapid investigation into the root cause of the failure mode. Subsequent simulations were performed for the full 3-D configuration in order to validate the 2-D findings since a planar geometry will not preserve the true volume to surface area ratio of the true 3-D configuration. 


\section{CRUNCH CFD ${ }^{\circledR}$ Numerical Framework}

The numerical simulations were performed using the CRUNCH CFD ${ }^{\circledR}$ multi-physics numerical $\operatorname{code}^{4-6}$ that has been developed by CRAFT Tech and is commercially licensed. This code is a threedimensional, unstructured finite-volume solver for viscous, generalized fluid simulations that allow hybrid element grids (i.e. tetrahedral, prismatic, pyramid, and hexahedral cells). Some of the key capabilities included in this framework that are relevant to the current and future efforts in modeling pyrovalve problems include: (i) accurate transient shock wave propagation in high pressure gas, (ii) strongly coupled conjugate heat transfer capability to model temperature rise in solid material, and (iii) multi-phase capability to model solid propellant particulates as well as molten metal that has eroded from the PCA casing.

\section{Numerical Results}

\section{D Planar Configuration}

Transient shock dynamic simulations for a planar 2-D cross-section of the PCA configuration were performed to understand the differences between single and dual firing cases. For these simulations, inviscid flow was assumed and the effect of the primer charge was modeled with a high pressure and temperature zone initialized in the region of the charges. The pressure and temperature levels $(82.7 \mathrm{MPa}$ and $2850 \mathrm{~K}$ ) were derived from an analytical solution of a closed-bomb problem for the complete burn of a typical NSI charge. The initial high pressure and temperature zones for the single and simultaneous dual firings are shown in Figure 1(a), Figure 2(a), Figure 3(a), and Figure 4(a), respectively. The flowfield is initially quiescent and atmospheric conditions are assumed outside of the high-pressure zones. In addition, a trace amount of $20 \mu \mathrm{m}$ diameter $\mathrm{Zr}-\mathrm{O}_{2}$ particles were uniformly distributed in the high pressure/temperature zones to track the particulate location since heat transfer from the particulate phase is expected to be a major factor in the gas burning through the booster cap.

The pressure contours for the single and simultaneous dual firings at $0 \mu \mathrm{s}, 5 \mu \mathrm{s}, 10 \mu \mathrm{s}$, and $15 \mu \mathrm{s}$ are shown in Figure 1 and Figure 2, respectively. It is clear from these figures that the pressure rise in the booster cap region for the simultaneous dual firing case reaches and sustains a much higher peak level than the single firing case due to interaction between the flow from each flame channel. In contrast, the pressure in the single firing case gets relief from the unused flow channel which is at a low ambient pressure. However, the high pressure in the booster cap region for the dual firing case effectively creates a stagnation zone and reverses the flow back into the flow channels.

The effect of shock interactions causing flow stagnation and eventually reversal becomes more evident when looking at the Mach number contours in Figure 5 and Figure 6. The single firing case shows a high Mach number in the booster cap cavity (Figure 5) while the corresponding Mach number for the dual simultaneous firing case is very low (Mach number colors are blue in the booster cavity). In contrast the gas temperature contours show large values of temperatures that arise from compression of the gas (see Figure 6(c) and (d)) particularly in the dual firing case.



(a)

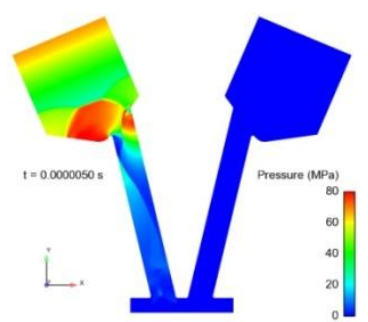

(b)

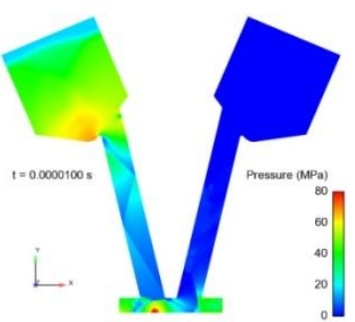

(c)



(d)

Figure 1: Pressure Distribution for Single Initiator Firing at 0, 5, 10, and $15 \mu \mathrm{s}$. 


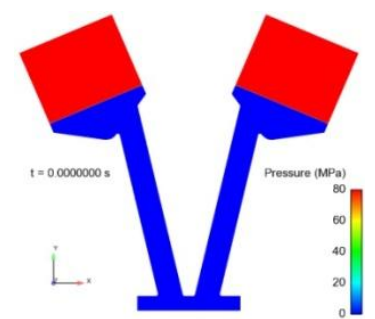

(a)

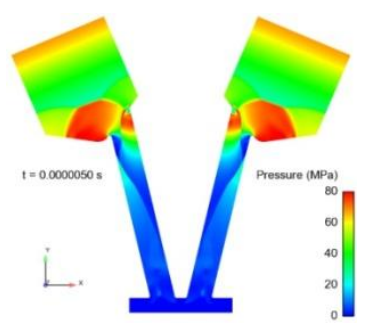

(b)

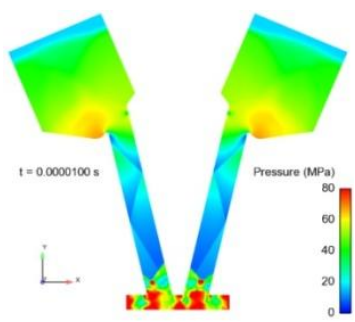

(c)



(d)

Figure 2: Pressure Distribution for Simultaneous Dual Firings at 0, 5, 10, and $15 \mu \mathrm{s.}$

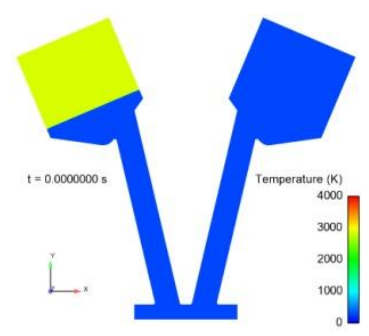

(a)



(b)



(c)



(d)

Figure 3: Temperature Distribution for Single Initiator Firing at 0, 5, 10, and $15 \mu \mathrm{s}$.

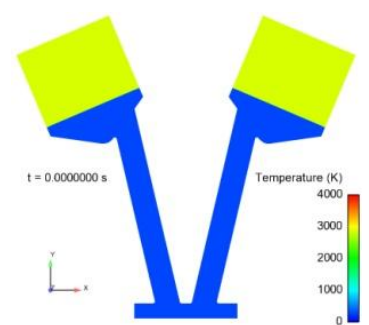

(a)

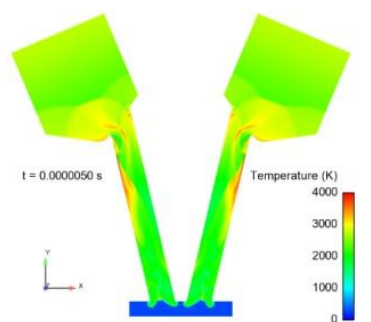

(b)

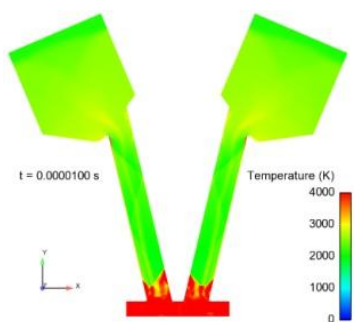

(c)

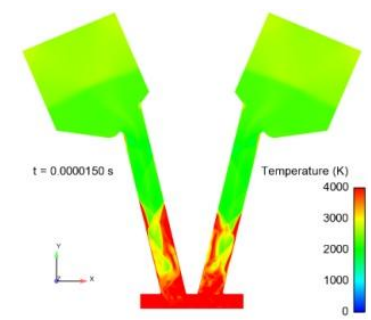

(d)

Figure 4: Temperature Distribution for Simultaneous Dual Firings at 0, 5, 10, and $15 \mu \mathrm{s}$.

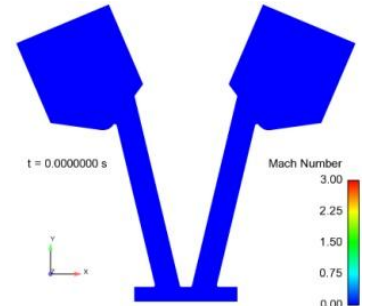

(a)

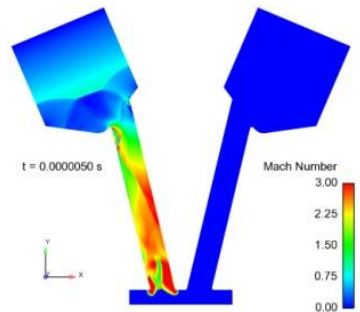

(b)



(c)

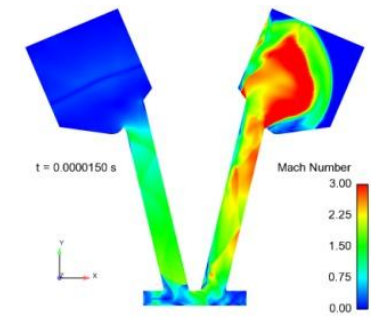

(d)

Figure 5: Mach Number Distribution for Single Firing at 0, 5, 10, and $15 \mu \mathrm{s}$.



(a)



(b)

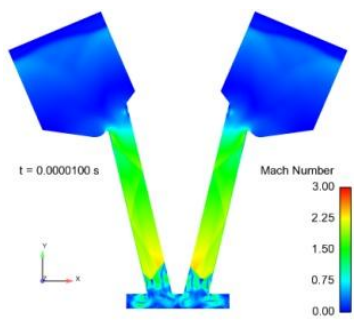

(c)

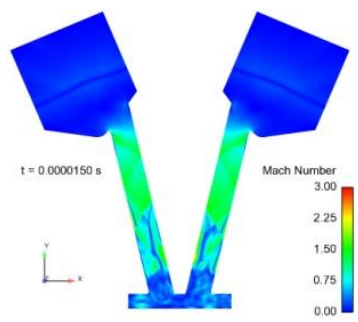

(d)

Figure 6: Mach Number Distribution Simultaneous Dual Firing at 0, 5, 10, and $15 \mu$ s. 
The flow stagnation and reversal in the dual firing case has an important effect on the convection of $\mathrm{Zr}-\mathrm{O}_{2}$ particulate phase into the booster cap region as shown in Figure 7 and Figure 8. In the single firing case since the flow can relieve itself into the unused flame channel and the gas velocity in the booster cap region remains high. As a consequence, the particles are able to travel unimpeded into the booster cavity and a high amount of particles impact and collect on the booster cap (see Figure 7(d)). In contrast for the dual firing case, since the flow stagnates and reverses itself, the movement of particles into the booster cap is hindered and a much smaller fraction of particles impinges on the booster cap (see Figure 8(d)); this could result in lower heat transfer to the booster end cap and less reliable burn through. Thus the simulations presented here provide a credible mechanism to explain the failure mode for dual simultaneous firings of NSI initiators.

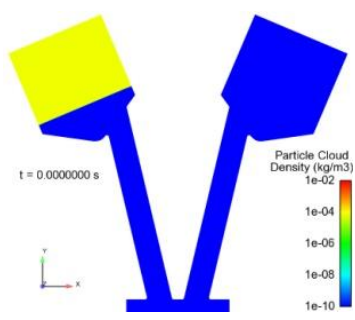

(a)

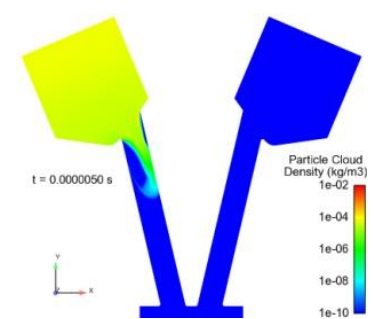

(b)



(c)

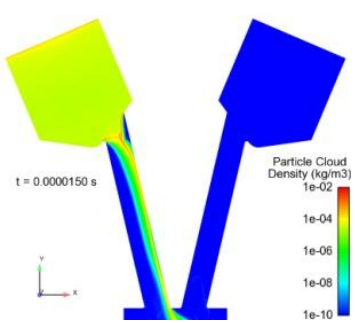

(d)

Figure 7: Particulate Distribution for Single Firing at 0, 5, 10, and $15 \mu \mathrm{s}$.



(a)

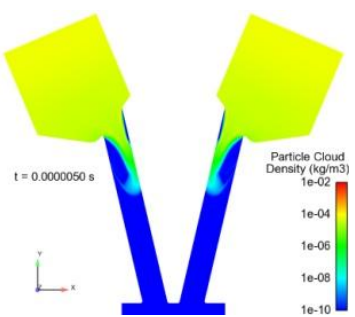

(b)



(c)

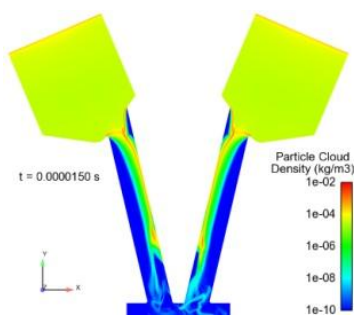

(d)

Figure 8: Particulate Distribution for Simultaneous Dual Firing at 0, 5, 10, and $15 \mu \mathrm{s}$.

\section{B. Simulations of Flow in a Tube with Oscillating Back Pressure}

Three-dimensional simulations of the complete PCA geometry were computed to confirm the qualitative results obtained with the 2-D planar configuration. The initialization of the problem was similar to the 2-D simulations in which inviscid flow was assumed and combustion of the propellant charges was modeled as a high pressure and temperature zone $(82.7 \mathrm{MPa}$ and $2850 \mathrm{~K})$. The initial high pressure and temperature zones for the single and simultaneous dual firings are shown in Figure 9(a), Figure 10(a), Figure 11(a), and Figure 12(a), respectively. The flow-field is initially quiescent and atmospheric conditions are assumed outside of the high-pressure zones. As done previously, a trace amount of $20 \mu \mathrm{m}$ diameter $\mathrm{Zr}-\mathrm{O}_{2}$ particles were uniformly distributed in the high pressure/temperature zones to track the particulate location since heat transfer from the particulate phase is expected to be a major factor in the gas burning through the booster cap. Note that for computational efficiency, halfplane symmetry was used and the hybrid-unstructured grid was relatively coarse with just under 2 million vertices.

The pressure, temperature, and Mach number contours on the symmetry plane and the booster cap are shown in Figure 9-Figure 16 Overall, these figures indicate a very similar solution to 2-D configuration; as in the 2-D case, the dual simultaneous firings show a flow stagnation and reversal due to shock interaction, while in the single firing case the gas continues to vent into the unused flame channel. However, the time scales for the 3-D configuration is roughly twice that of the 2-D configuration (the figures only show up to $24 \mu \mathrm{s}$ ). The 2-D approximation does not preserve the true volume to surface area 
ratio of the true 3-D configuration, particularly in the booster cavity, and therefore may have underestimated the time-scale of the problem.

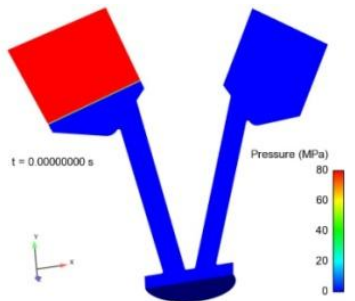

(a)

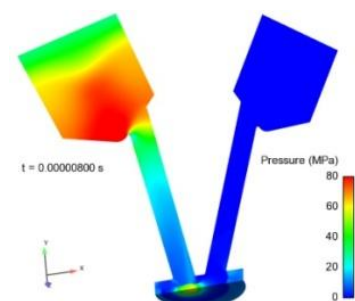

(b)

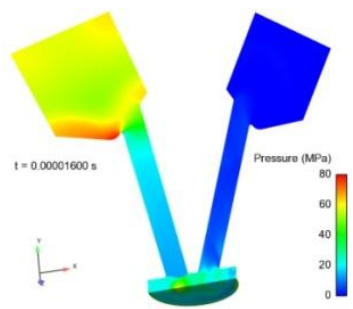

(c)

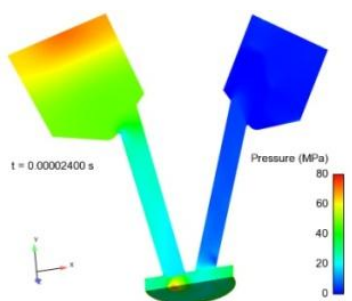

(d)

Figure 9: Pressure distribution for single initiator firing at $0,8,16$, and $24 \mu \mathrm{s}$.

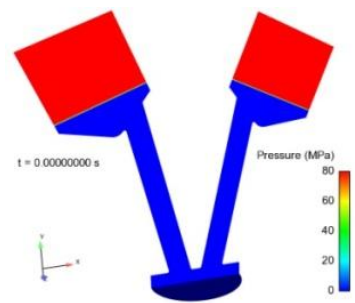

(a)

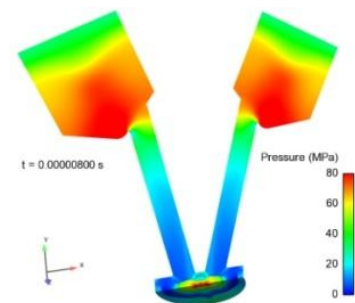

(b)

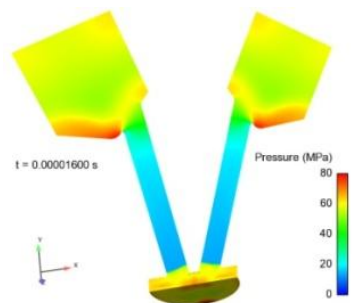

(c)

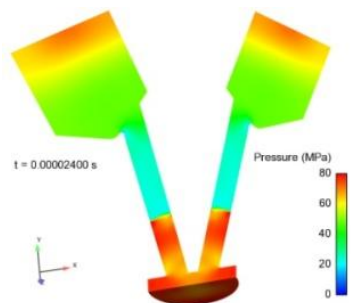

(d)

Figure 10: Pressure Distribution for simultaneous dual firings at 0, 8, 16, and $24 \mu \mathrm{s}$.

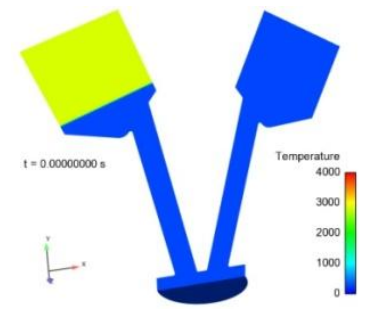

(a)

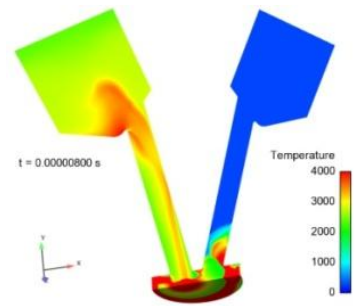

(b)

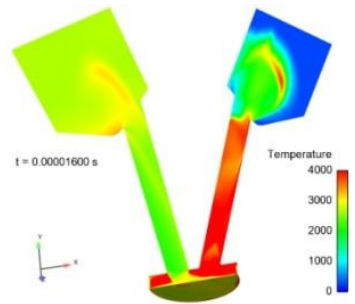

(c)

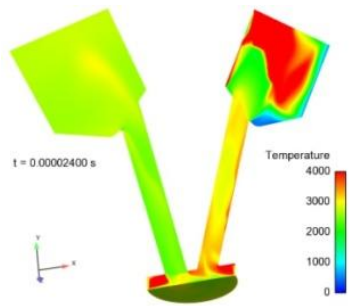

(d)

Figure 11: Temperature distribution for single initiator firing at $0,8,16$, and $24 \mu \mathrm{s}$.

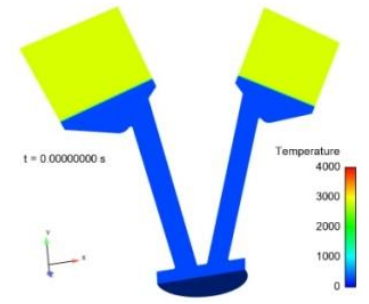

(a)

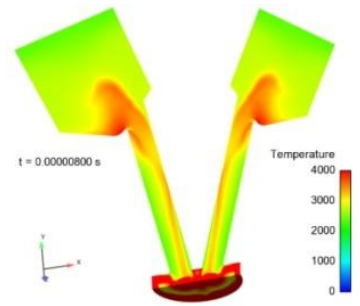

(b)

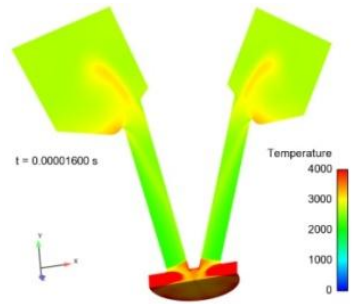

(c)

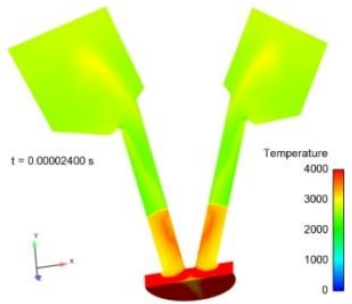

(d)

Figure 12: Temperature distribution for simultaneous dual firings at $0,8,16$, and $24 \mu$ s.

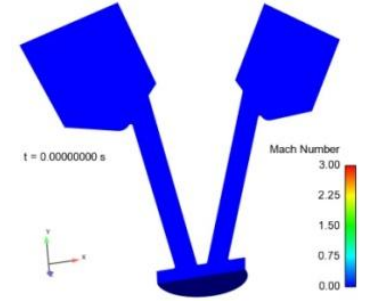

(a)

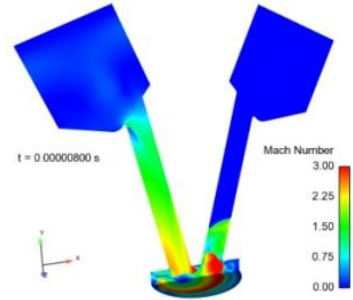

(b)

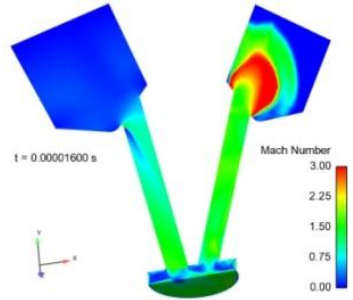

(c)

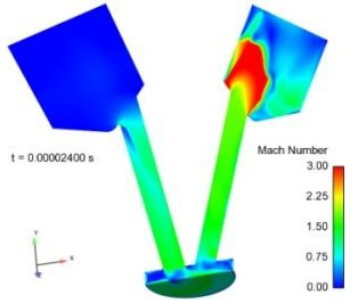

(d)

Figure 13: Mach number distribution for single firing at $0,8,16$, and $24 \mu$ s. 


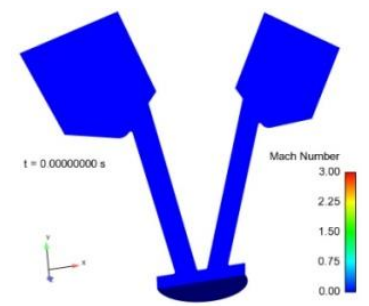

(a)

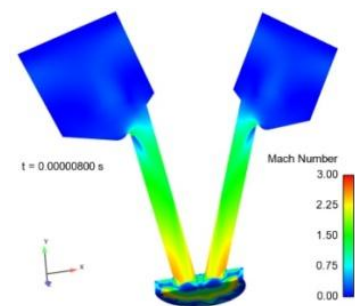

(b)

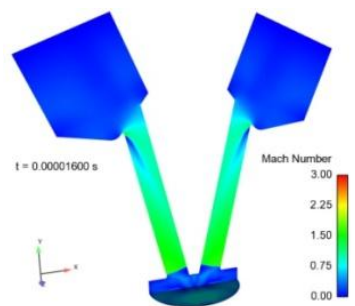

(c)

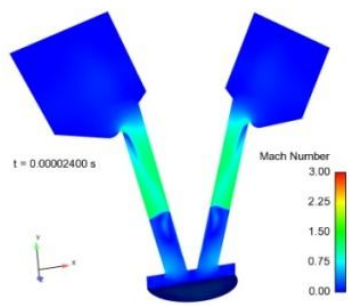

(d)

Figure 14: Mach number distribution for simultaneous dual firing at $0,8,16$, and $24 \mu \mathrm{s}$.

The flow stagnation and reversal in the dual firing case has an important effect on the transport of the $\mathrm{Zr}-\mathrm{O}_{2}$ particulate phase into the booster cap region as shown in Figure 15 and Figure 16 for the single and simultaneous dual firing scenarios. Here, the flow stagnation from the shock interaction has a less dramatic effect on the particulate phase as compared to the 2-D planar configuration since it appears that both firing scenarios enable a substantial amount of particles to impact the booster cap. However, the flow reversal causes the convection of particles through the flame channels to stop and reverse in direction. This begins at 30-40 $\mu$ s and can be seen in Figure 16(d). The total amount of the particulate impacting the booster cap in both firing scenarios can be measured by integrating the total mass of particles within a region near the booster cap; the location of the integration zone with the booster cavity is shown in Figure 17(a). The time-varying total mass of particles in the integration zone normalized by the mass of particles contained within a single initiator charge is shown in Figure 17(b) for both the single and simultaneous dual firing scenarios. After $100 \mu$ s the dual firing case shows half the amount of particles contained in the volume near the booster cap than the single firing case despite having twice the amount of particles. In the single firing case since the flow can relieve itself into the unused flame channel and the gas velocity in the booster cap region remains high. As a consequence, the particles are able to travel unimpeded into the booster cavity and a high amount of particles impact and collect on the booster cap. In contrast for the dual firing case, since the flow stagnates and reverses itself, the movement of particles into the booster cap is hindered and a much smaller fraction of particles impinges on the booster cap. Therefore, the fundamental hypothesis for the failure mode of the simultaneous dualfiring scenario is still valid.

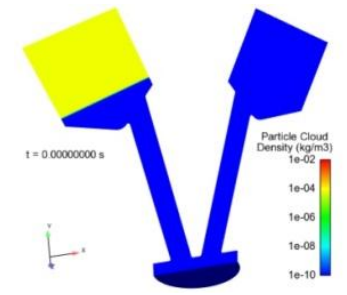

(a)

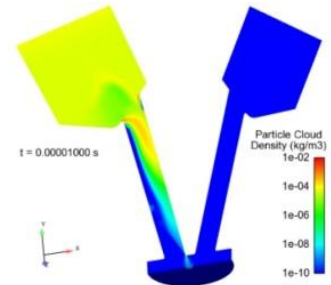

(b)

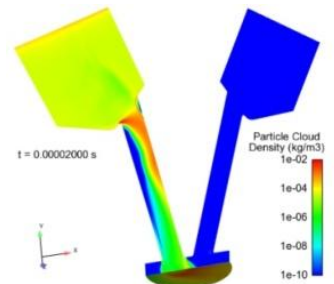

(c)

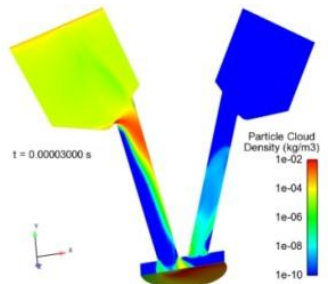

(d)

Figure 15: Particulate distribution for single firing at $0,10,20$, and $30 \mu \mathrm{s}$.

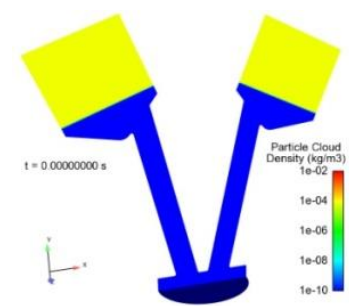

(a)

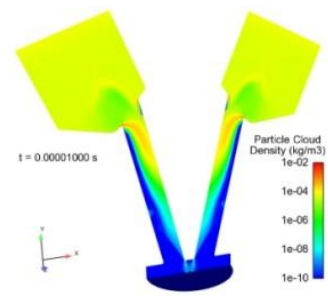

(b)

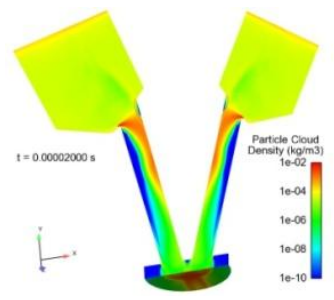

(c)

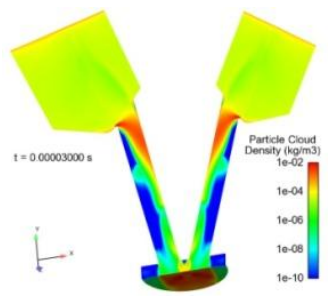

(d)

Figure 16: Particulate distribution for simultaneous dual firing at $0,10,20$, and $30 \mu s$. 


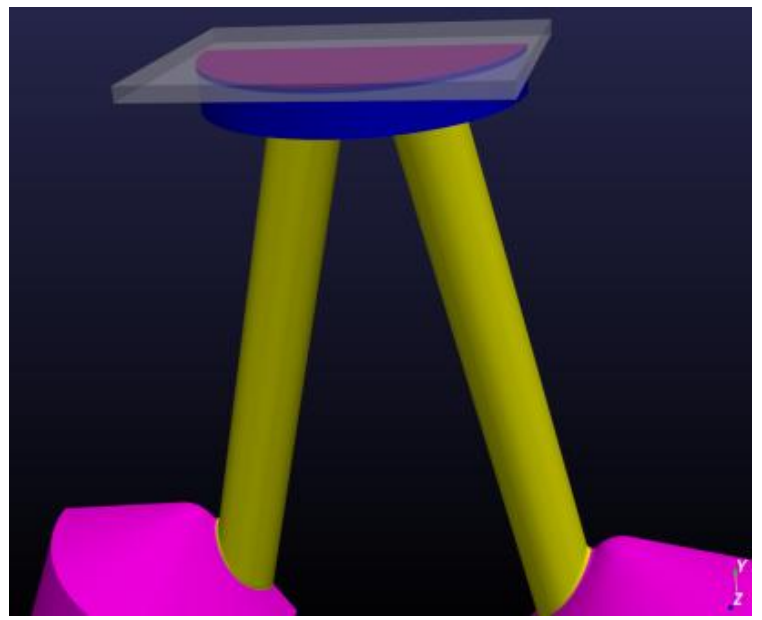

(a)

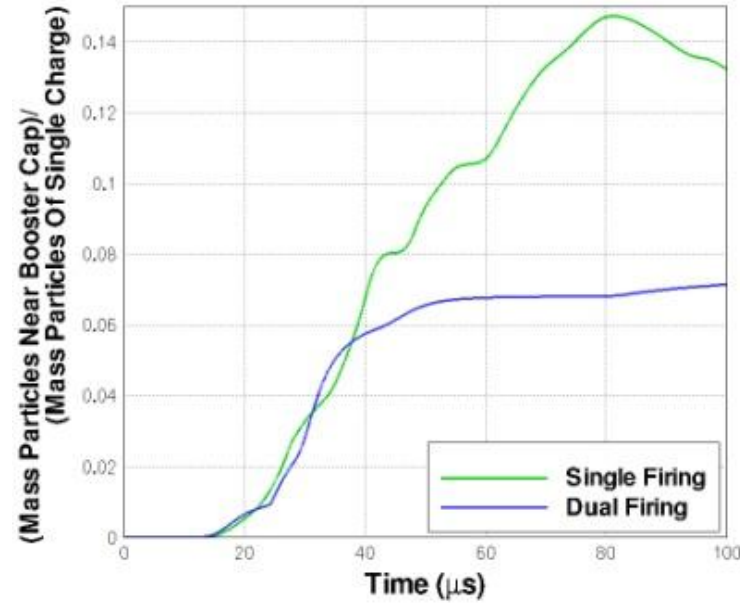

(b)

Figure 17: Mass of particles accumulating within a zone near the booster cap (a) integration zone shown in grey and (b) the total mass of particles within the integration zone over time for both firing scenarios.

\section{2-D Planar Configuration With Conjugate Gradient Heat Transfer}

To estimate the convective heat flux into the solid and the effective heat transfer coefficient at the interface, the Navier-Stokes equations are solved for a turbulent flow inside the PCA simultaneously with the thermal equations in the stainless-steel casing of the PCA. These fully coupled simulations were performed for the single and simultaneous dual firings with the 2-D planar configuration. The schematic of the stainless-steel casing used in this study is show in Figure 18. The density, thermal conductivity, and specific heat of the stainless-steel casing were set to $7900 \mathrm{~kg} / \mathrm{m}^{3}, 50 \mathrm{~W} / \mathrm{m}-\mathrm{K}$, and $460 \mathrm{~J} / \mathrm{kg}-\mathrm{K}$, respectively. The fluid grid for these simulations was refined to ensure $\mathrm{y}^{+}$values less than 1 .

The temperature profiles showing the heating of the casing material at the center of the booster cap are given in Figure 19 at $8 \mu \mathrm{s}, 14 \mu \mathrm{s}$, and $20 \mu$ s for the simultaneous dual firing scenario. It can be seen that the thermal penetration depth into the solid is minimal and only the metal very close to the interface heats up. The profiles for the single firing scenario are very similar. The average temperature of the booster cap on the hot-gas side is shown is shown as a function of time in Figure 20(a). From Figure 20(a), the temperature on the hot gas side reaches a slightly higher level, around $1100 \mathrm{~K}$, for the simultaneous dual firing while it reaches a value of approximately $800 \mathrm{~K}$ for the single firing case. The total heat flux profiles on the booster cap are given in Figure 20(b). These profiles indicate a peak heat flux of $2,000 \mathrm{MW} / \mathrm{m}^{2}$ and $1,400 \mathrm{MW} / \mathrm{m}^{2}$ for the dual and single firing scenarios, respectively. After reaching this peak around $10 \mu \mathrm{s}$, the heat flux drops rapidly and is approximately $900 \mathrm{MW} / \mathrm{m}^{2}$ and 600 $\mathrm{MW} / \mathrm{m}^{2}$ respectively at $20 \mu \mathrm{s}$. In the dual firing scenario, the stagnation zone in the booster cavity results in higher temperature than the single firing scenario due to increased compression. Despite the fact the flow is stagnated, the heat flux is larger for the dual firing case due to this higher temperature. However, as seen in Figure 20(c), the heat transfer coefficient is similar for the dual and single firing scenarios. 


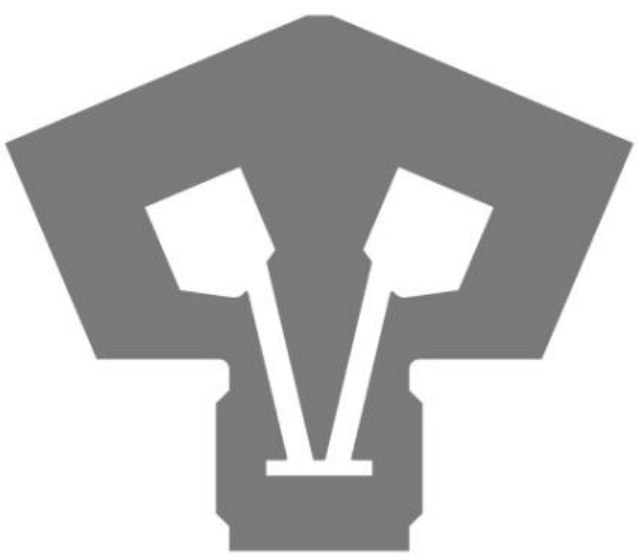

Figure 18: Schematic of Stainless-Steel Casing.

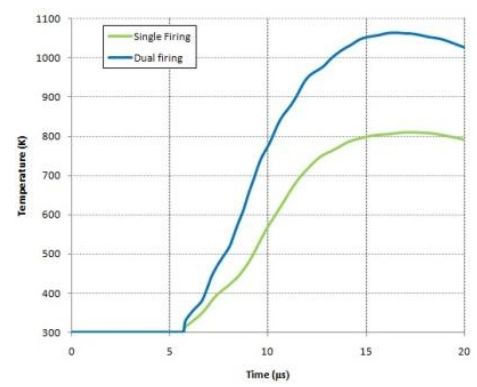

(a) Average booster cap temperature (hot gas side)

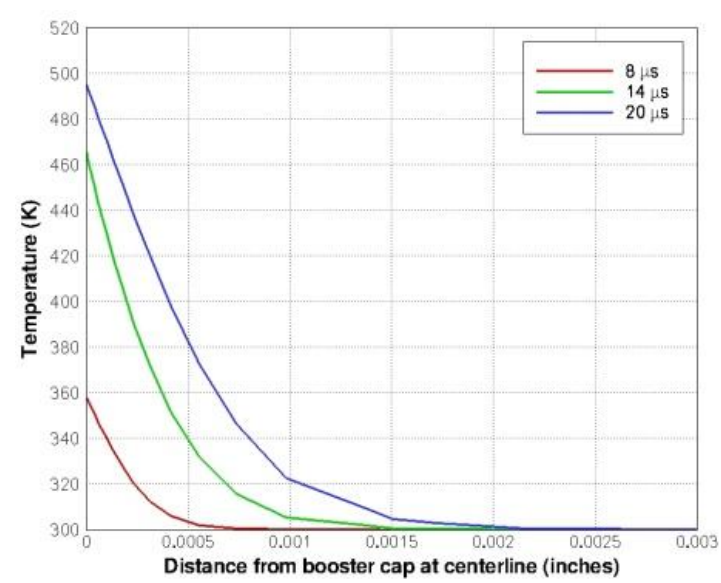

Figure 19: Temperature Profiles in the Stainless Steel Casing at the Center of the Booster Cap.

Figure 20: (a) Average Temperature, (c) Total Heat Flux, and (c) Heat Transfer Coefficient on the Booster Cap.

The temperature profiles plotted in Figure 19 can be qualitatively validated against the analytical solution for the temperature profile through a semi-infinite solid with a constant heat flux. This analytical solution is given by

$$
T(x, t)=T_{i}+\frac{2 q_{s} \sqrt{\alpha t / \pi}}{k} \exp \left(\frac{-x^{2}}{4 \alpha t}\right)-\frac{q_{s} x}{k} \operatorname{erfc}\left(\frac{x}{2 \sqrt{\alpha t}}\right)
$$

where $T_{i}$ is the initial temperature of the solid $(\mathrm{K}), q_{s}$ is the constant surface heat flux, $k$ is the thermal conductivity $(\mathrm{W} / \mathrm{m}-\mathrm{K})$, and $\alpha$ is the thermal diffusivity $\left(\mathrm{m}^{2} / \mathrm{s}\right)$. The temperature profiles computed from this analytical expression for constant surface heat fluxes of 400 and $800 \mathrm{MW} / \mathrm{m}^{2}$ are plotted in Figure 21(a) and (b), respectively. Good agreement between the analytic profiles and the profile from the CFD simulation with conjugate gradient heat transfer can be seen when comparing Figure 19 with these figures. Figure 22 shows the analytical temperature profiles at 200, 400,600, and $800 \mu$ s for a constant surface heat flux of $600 \mathrm{MW} / \mathrm{m}^{2}$. At $800 \mu \mathrm{s}$ the "hot" side of the booster cap nearly reaches $1800 \mathrm{~K}$ whereas the cold side exceeds $1000 \mathrm{~K}$. These temperature levels and time-scales are more aligned with the experimental results and indicate that the convective heat transfer could potentially account for the 
substantial temperature rise if the heat flux can be maintained for the entire duration of the firing cycle. The burn through of end-cap may be a combination of convective heating and multi-phase effects from particle impact onto the booster cap which will locally transfer energy both due to its high momentum as well hot temperatures. This could potentially explain the difference between single and simultaneous dual firings.

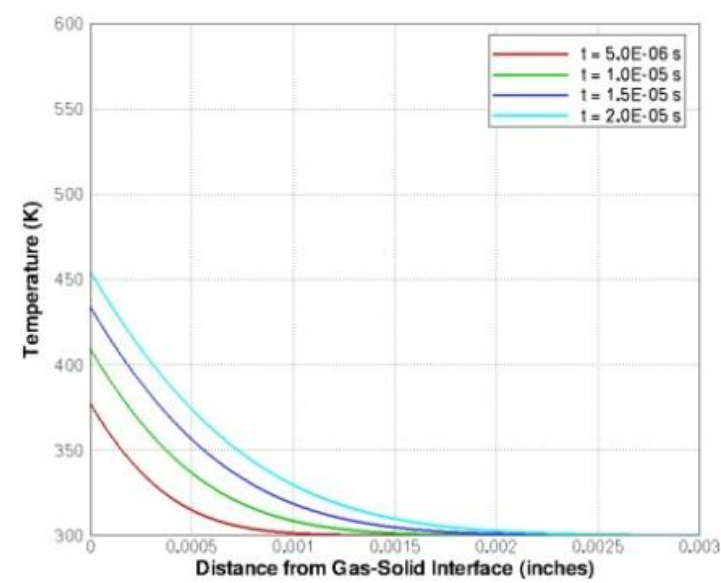

(a) Constant Heat flux of $400 \mathrm{MW} / \mathrm{m}^{2}$

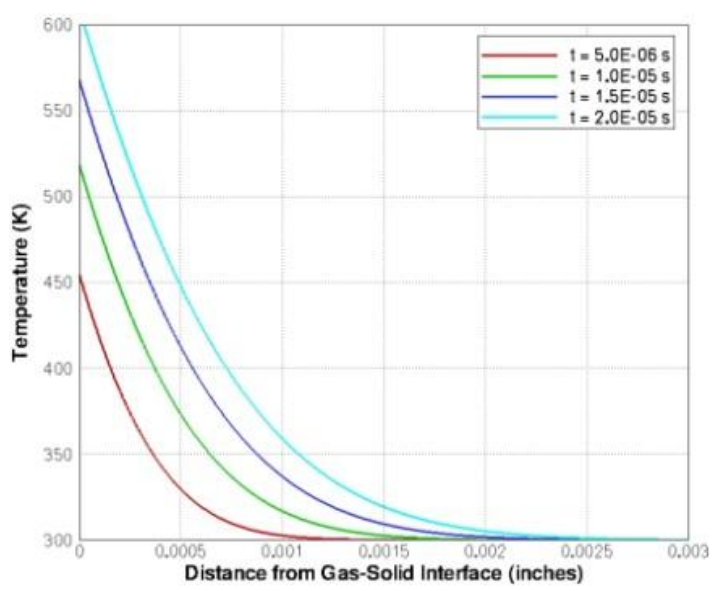

(b) Constant heat flux of $800 \mathrm{MW} / \mathrm{m}^{2}$

Figure 21: Temperature Profiles Computed from the Analytic Solution for a Semi-Infinite Solid with a Constant Surface Heat Flux.

\section{Conclusion}

The simulations performed on the SS PCA design were able to identify the cause for the potential failure mode in dual simultaneous initiator firings and achieve the objective of this effort. The results indicate that the failure mode may be caused by flow interactions between the flame channels. The shock waves from each initiator interact in the booster cap region resulting in a high pressure zone that causes flow reversal in the flame channel. In contrast, the single firing case shows continuous venting of high velocity gas into the unused flame channel. It is hypothesized in the PCA design community that the heat transfer and momentum of the particulate phase impacting the booster cap may be a primary cause for its burn through and that convective heat transfer may play a relatively much smaller role. The simulation results presented here indicate that the flow stagnation in the dual simultaneous firing case reduces the mass of particulate phase reaching the booster cap by 50\% compared to the single firing case and hence these results are consistent with the hypothesis for booster cap burn-through.

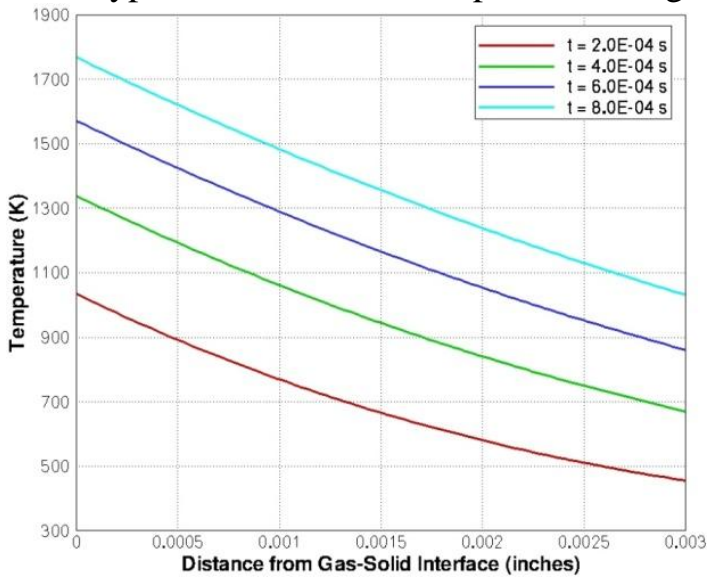

10

American Institute of Aeronautics and Astronautics 
Figure 22: Temperature profiles computed from the analytic solution for a semi-infinite solid with a constant heat flux of $600 \mathrm{MW} / \mathrm{m}^{2}$.

\section{Acknowledgments}

This work was performed under NASA Phase I SBIR Contract No. NNX11CG13P with Mr. Regor Saulsberry as the Program Manager. The first three authors gratefully acknowledge the technical help and support also provided by Robert Garcia (NESC, Propulsion Technical Fellow), and Steve Rickman (NESC, Passive Thermal Technical Fellow) during the course of this effort. We would also like to thank Ms. Sandra Vebra, Senior Program Manager, Conax Florida Corporation for her help and cooperation.

\section{References}

${ }^{1} Z$ Zenz, Z. D., Schummer, S.W., Pender, A., and Mizukami, M., "Stainless Steel Primer Chamber Assemblies for Dual Initiated Pyrovalves," Presented at the 6th Modeling and Simulation, 4th Liquid Propulsion, 3rd Spacecraft Propulsion Joint Subcommittee Meeting, Orlando, FL, 8-12 December 2008.

${ }^{2}$ Hagopian, M., Saulsberry, R., and McDougle, S., "NESC Independent Assessment of Pyrovalve Ground Test Anomalies," AIAA-2008-4798, 44 ${ }^{\text {th }}$ AIAA/ASME/SAE/ASEE Joint Propulsion Conference and Exhibit, Hartford, CT, July 21-23, 2008.c

${ }^{3}$ Saulsberry, R. L., McDougle, S. H, Garcia, R., Johnson, E. L., Sipes, W., Rickman, S., and Hosangadi, A., "Innovative Comparison of Transient Ignition Temperature at the Booster Interface, New Stainless Steel Pyrovalve Primer Chamber Assembly "V" (PCA) Design versus the Current Aluminum "Y" PCA Design," AIAA-2011-5732, 47th AIAA/ASME/SAE/ASEE Joint Propulsion Conference \& Exhibit, Orlando, FA, July 31-Aug.3, 2011.

${ }^{4}$ Hosangadi, A., Lee, R.A., York, B.J., Sinha, N. and Dash, S.M., "Upwind Unstructured Scheme for Three-Dimensional Combusting Flows," Journal of Propulsion and Power, Vol. 12, No. 3, pp. 494-503, May-June 1996.

${ }^{5}$ Hosangadi, A., Lee, R.A., Cavallo, P.A., Sinha, N., and York, B.J., "Hybrid, Viscous, Unstructured Mesh Solver for Propulsive Applications," AIAA-98-3153, 34th AIAA/ASME/SAE/ASEE Joint Propulsion Meeting and Exhibit, Cleveland, OH, July 13-15, 1998.

${ }^{6}$ Sachdev, J.S., Ahuja, V., Hosangadi, A., and Allgood, D.C., "Analysis of Flame Deflector Spray Nozzles in Rocket Engine Test Stands," AIAA-2010-6972, 46th AIAA/ASME/SAE/ASEE Joint Propulsion Meeting and Exhibit, Nashville, TN, July 25-28, 2010. 


\title{
Failure Mode Analysis of V-Shaped Pyrotechnically Actuated Valves
}

\author{
Jai Singh Sachdev, Ashvin Hosangadi, and \\ James Chenoweth, CRAFT Tech
}

and

Regor L. Saulsberry and Stephen H. McDougle NASA Johnson Space Center White Sands Test

Combustion Research and Flow Technology, Inc.

6210 Keller's Church Rd.

Pipersville, PA 18947

www.craft-tech.com

(215) 766-1520 


\section{Pyrotechnic Valve Operation}

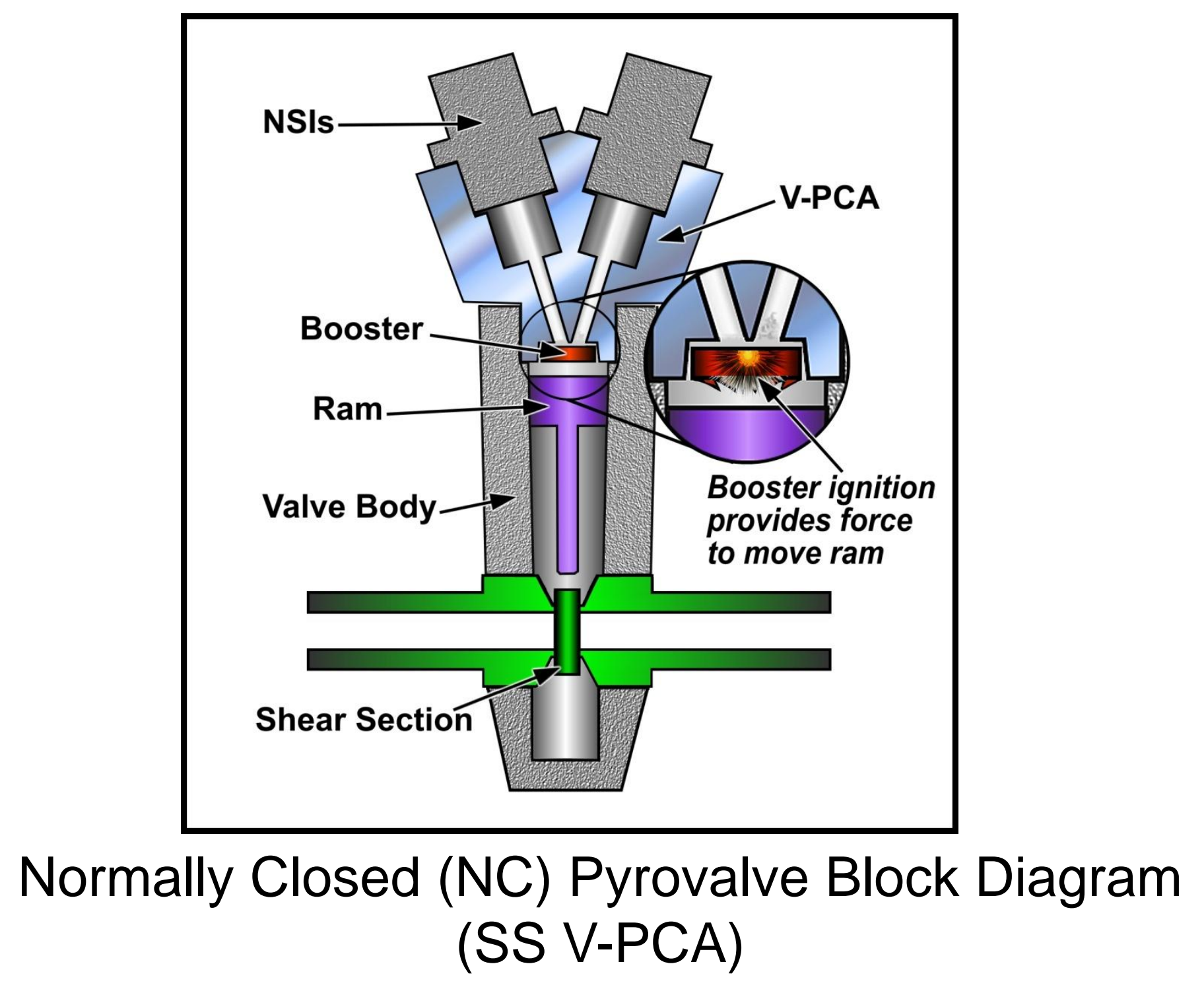




\section{Y-Shaped PCA Design}

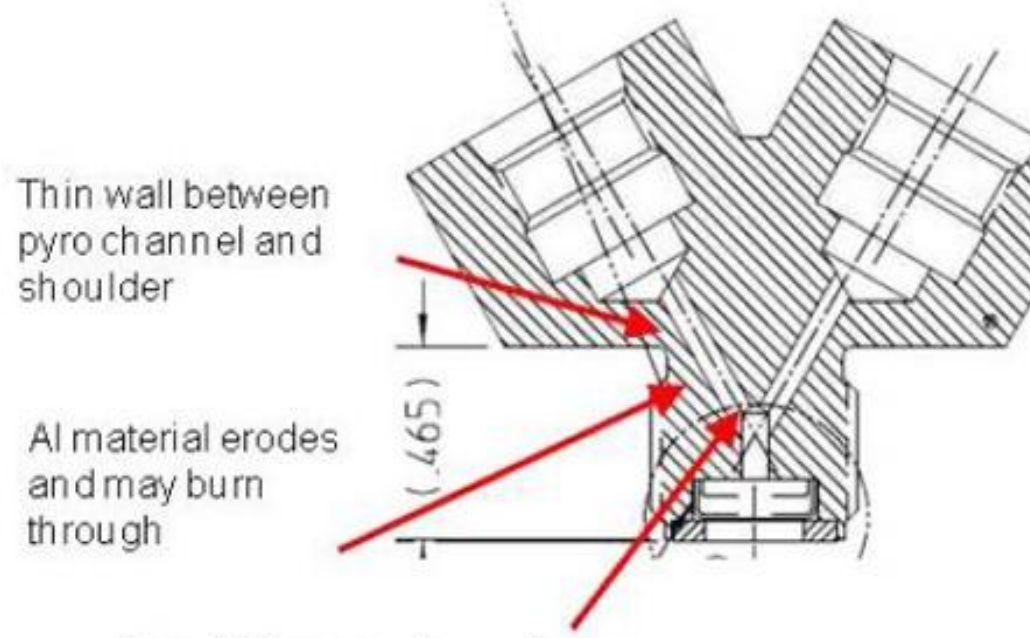

Turn / $Y$ in pyro channel may compromise ignition

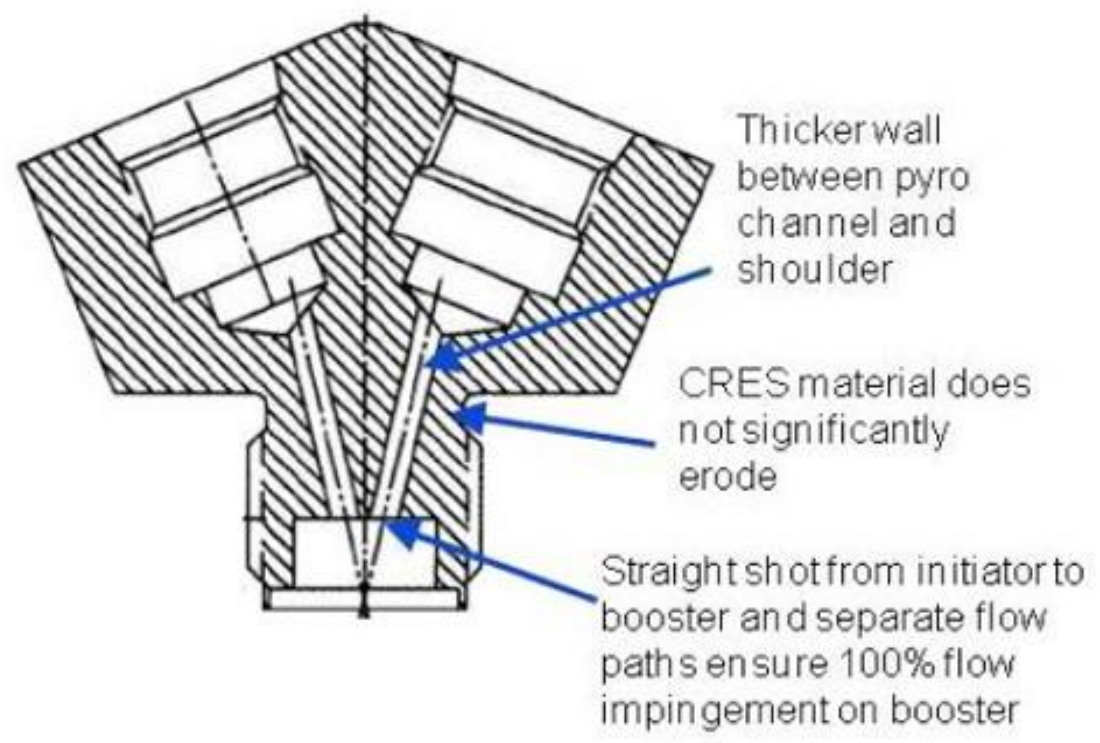

MSL: CRES-V

\section{HERITAGE}

- Heritage "Y" shaped aluminum designs have been found to have some deficiencies:

- In 2008, the NASA Engineering \& Safety Center (NESC) studied four spacecraft pyrovalve anomalies that occurred during ground testing

- The common aluminum (Al) primer chamber assembly (PCA) was used with dual NASA Standard Initiators (NSIs)

- The AL Y-PCA demonstrated the ability to consistently ignite a booster with a single NSI firing, or when the firing skew is greater than $2 \mathrm{~ms}$

- However, the nearly simultaneous (separated by less than $80 \mu \mathrm{s}$ ) firing of both initiators failed to ignite the booster charge

- As result, the Mars Science Laboratory (MSL) project team decided to redesign the PCA

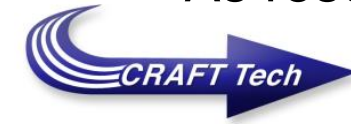




\section{V-Shaped PCA Design}

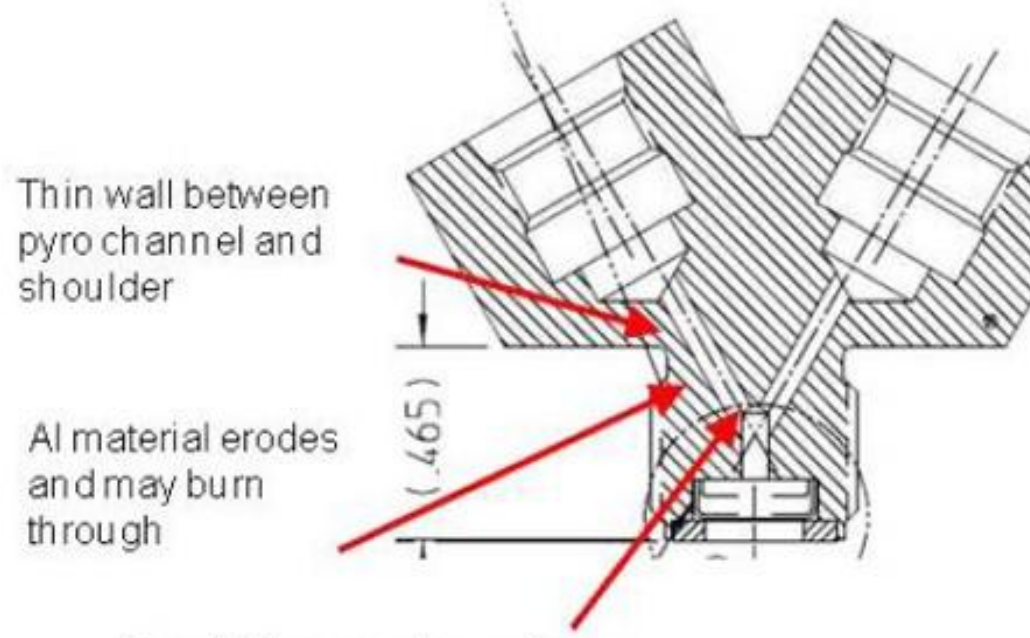

Turn / $Y$ in pyro channel may compromise ignition

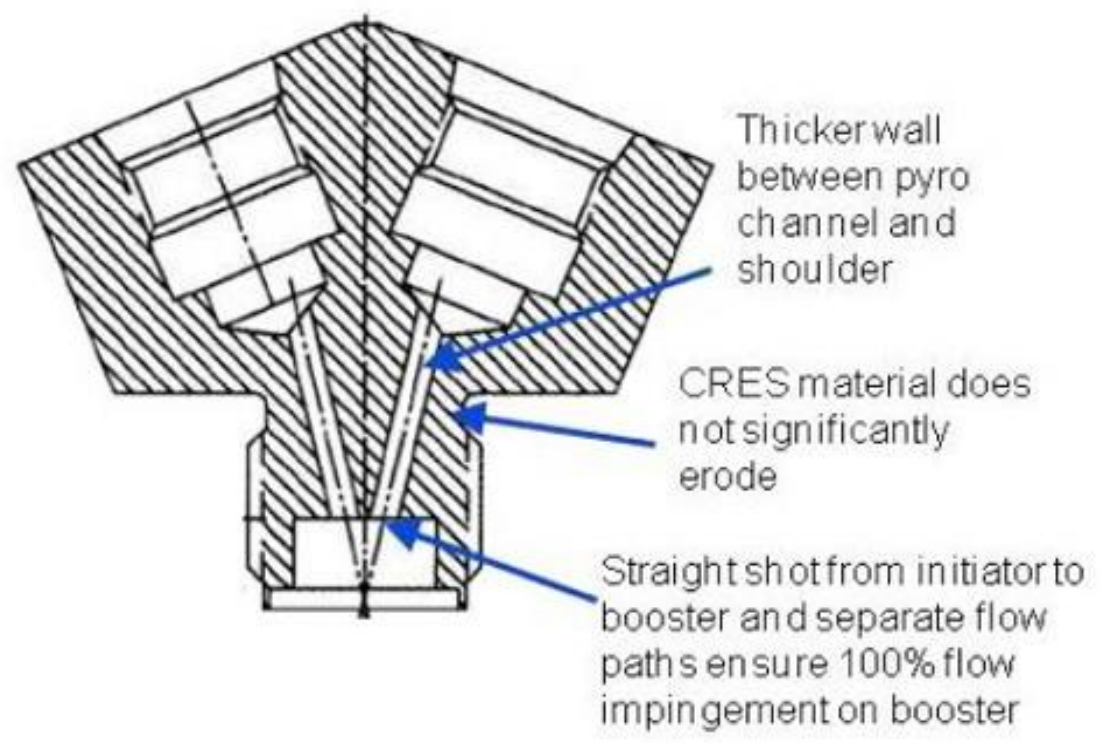

MSL: CRES-V

\section{HERITAGE}

- "V" shaped Stainless steel redesign rectified many of the issues with the heritage design:

- PCA material was changed from aluminum (Al) to stainless steel (SS) to avoid melting, distortion, and potential leakage of the NSI flow passages

- The flow passages modified from a Y-shaped configuration (Y-PCA) to a V-shape (V-PCA)

- Energy transferred more efficiently from the NSIs to the booster

- Development and qualification testing of the new design clearly demonstrated faster booster ignition times

- Measurable performance improvement over AL Y-PCAs: higher temperature at booster interface (over $600^{\circ} \mathrm{F}$ ) in half the time

- Higher temperature provides added assurance of booster propellant ignition 


\section{Failure Mode for Dual Simultaneous Initiator Firings}

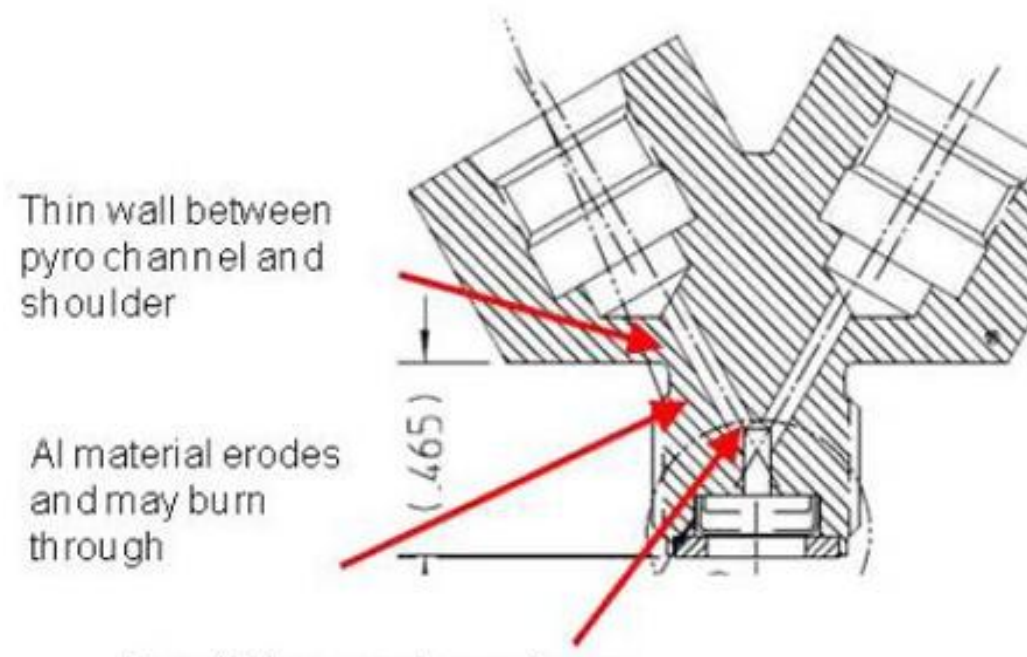

Turn / $Y$ in pyro channel may compromise ignition

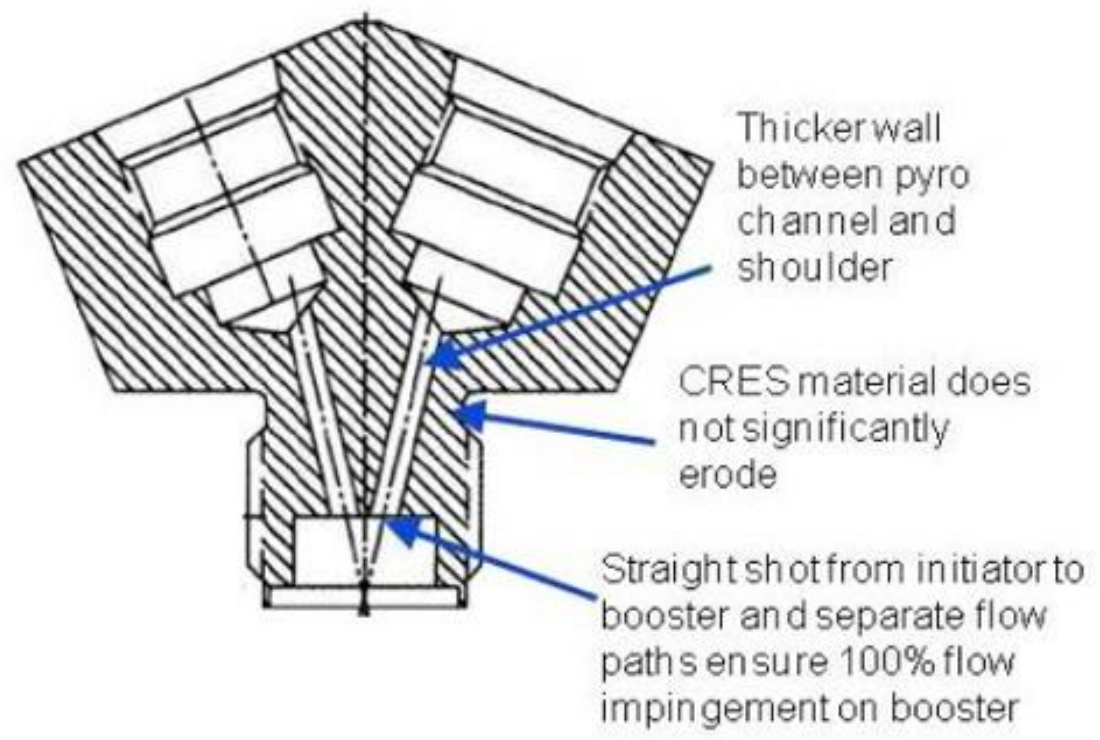

MSL: CRES-V

\section{HERITAGE}

- However a credible failure mode still present for dual simultaneous initiator firings:

- Testing showed that dual simultaneous (within $20 \mu \mathrm{s}$ ) firing of the redundant NSIs significantly reduces the performance of both PCA designs

- Dual simultaneous firings do not reliably ignite the booster charge

- The temperature at the booster covers were very low

- A credible failure modes still remain for dual simultaneous initiator (NSI) firings

- This is counterintuitive since we would normally expect higher energy from dual firings as compared to a single NSI firing

- In contrast, single firings of the initiator provided large temperatures and consistent ignition

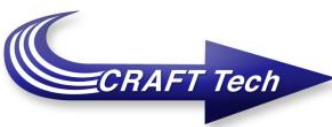




\section{Objective of Current Study}

- The unsteady gas-dynamic interactions between each leg of the flame channel may play a critical role in the optimal operation of the PCA

- Emphasis is on the gas-dynamic interactions between each flame channel

- Simplifications made for a quicker and more efficient investigation:

- Heat transfer to the solid walls was neglected and inviscid gas assumed

- Afterburning/combustion of the particulate phase was neglected

- 2-D planar and 3-D with half-plane symmetry and relatively coarse grid ( $<2$ million cells) configurartions considered

- Preliminary investigation for a 1-D configuration led to working hypothesis:

For a dual-firing case, shock waves from each initiator interact with each other and prevent the gas and particulate velocity from rising and in fact cause the flow to stagnate. This reduces the heat transfer to the booster cap both because the solid propellant particles do not reach the booster cap, and the heat transfer coefficient is reduced due to lack of convective effects. Hence a failure mode results.

- Initiator regions:

- Pressure and temperature of 82.737085 MPa and $2856.56 \mathrm{~K}$

- Uniform distribution of $20 \mu \mathrm{m}$ particles with density of $5890 \mathrm{~kg} / \mathrm{m}^{3}$ and loading factor of $1 e-6$

- Otherwise:

- Pressure and temperature of 0.1 $\mathrm{MPa}$ and $300 \mathrm{~K}$

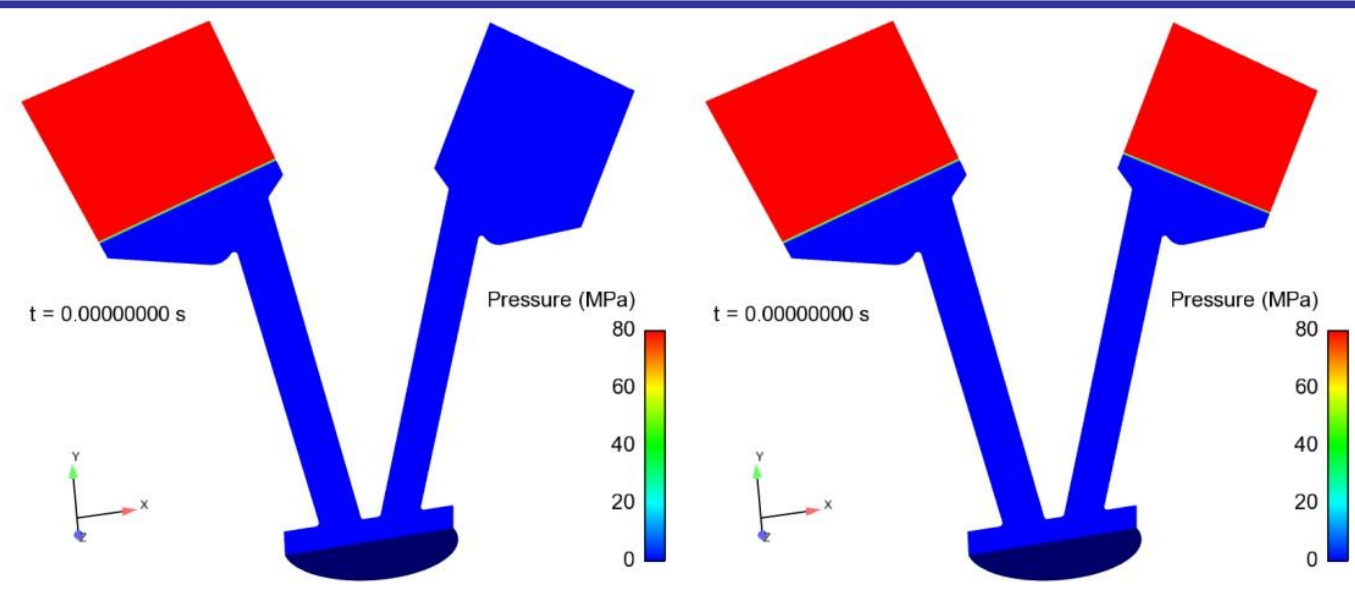




\section{CRUNCH CFD Multi-Physics}

- Vertex-based finite volume scheme on multi-element unstructured meshes

- Implicit time integration with dual-time-stepping for unsteady flows

- Dynamic grid capabilities and adaptive mesh refinement with CRISP CFD ${ }^{\circledR}$

- Advanced thermo-chemistry for combusting real gases

- Generalized non-ideal formulations for gas/liquid mixtures and supercritical fluids

- Generalized gas/bulk liquid framework

- Non-equilibrium particle/droplet phase (Eulerian formulation)

CRUNCH CFD Multi-Disciplinary Framework:

- Domain specialized solvers brought together under single umbrella

- Use each solver in respective areas of expertise

- Solvers communicate at boundaries or in overlapping domains

- Specialized communication API to enable interaction

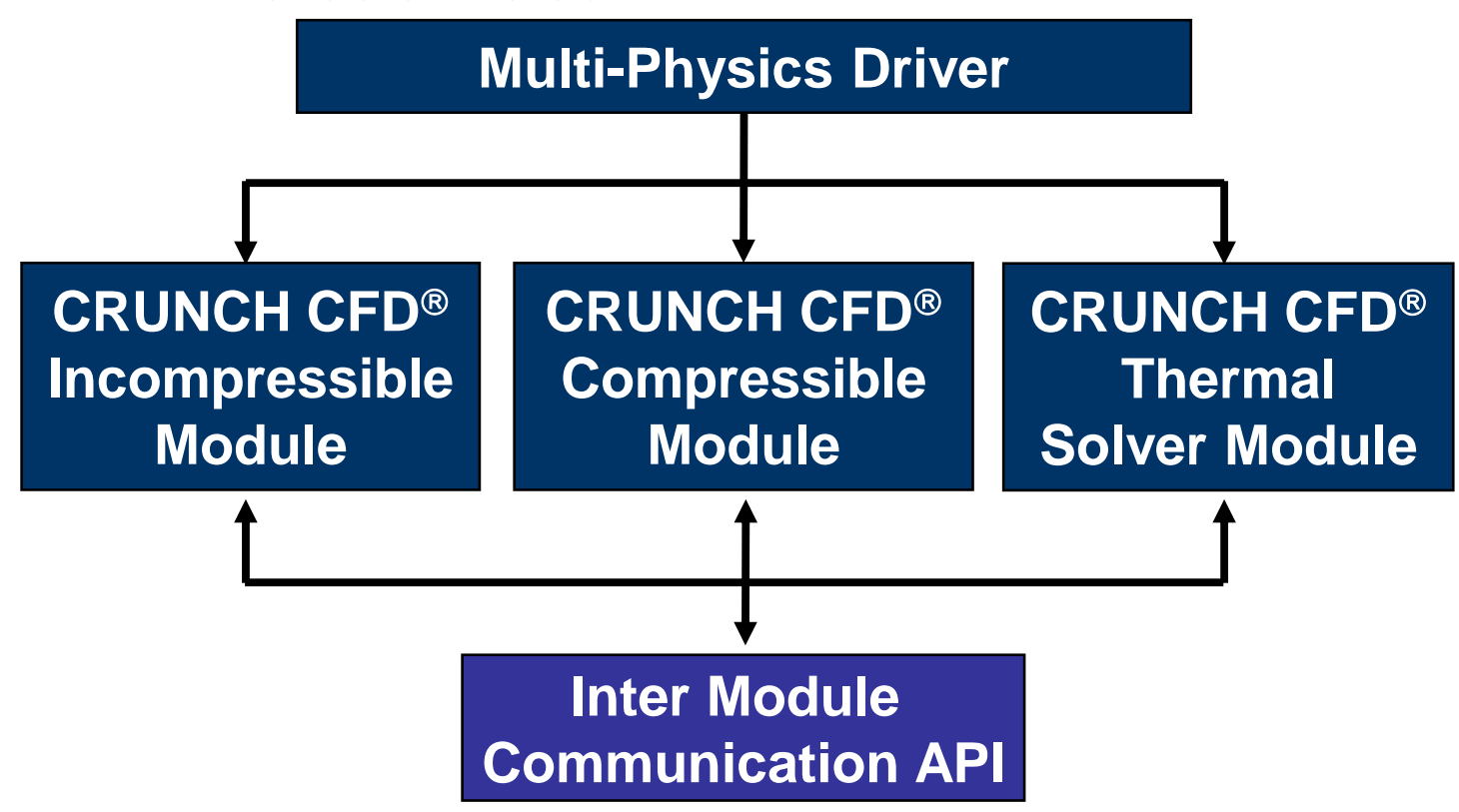




\section{2-D Planar Results: Pressure Contours}

- The pressure rise in the booster cap region for the simultaneous dual firing case reaches and sustains a much higher peak level than the single firing case

- In the single firing case, the pressure is relieved into the unused flow channel and charge area

- The flow channels are offset in the radial direction from the end of the curved surface in the initiators

- This creates a large pressure rise which causes the flow to turn into channel at an angle

- This turning has an implication on the paths the particles take through the flow channel
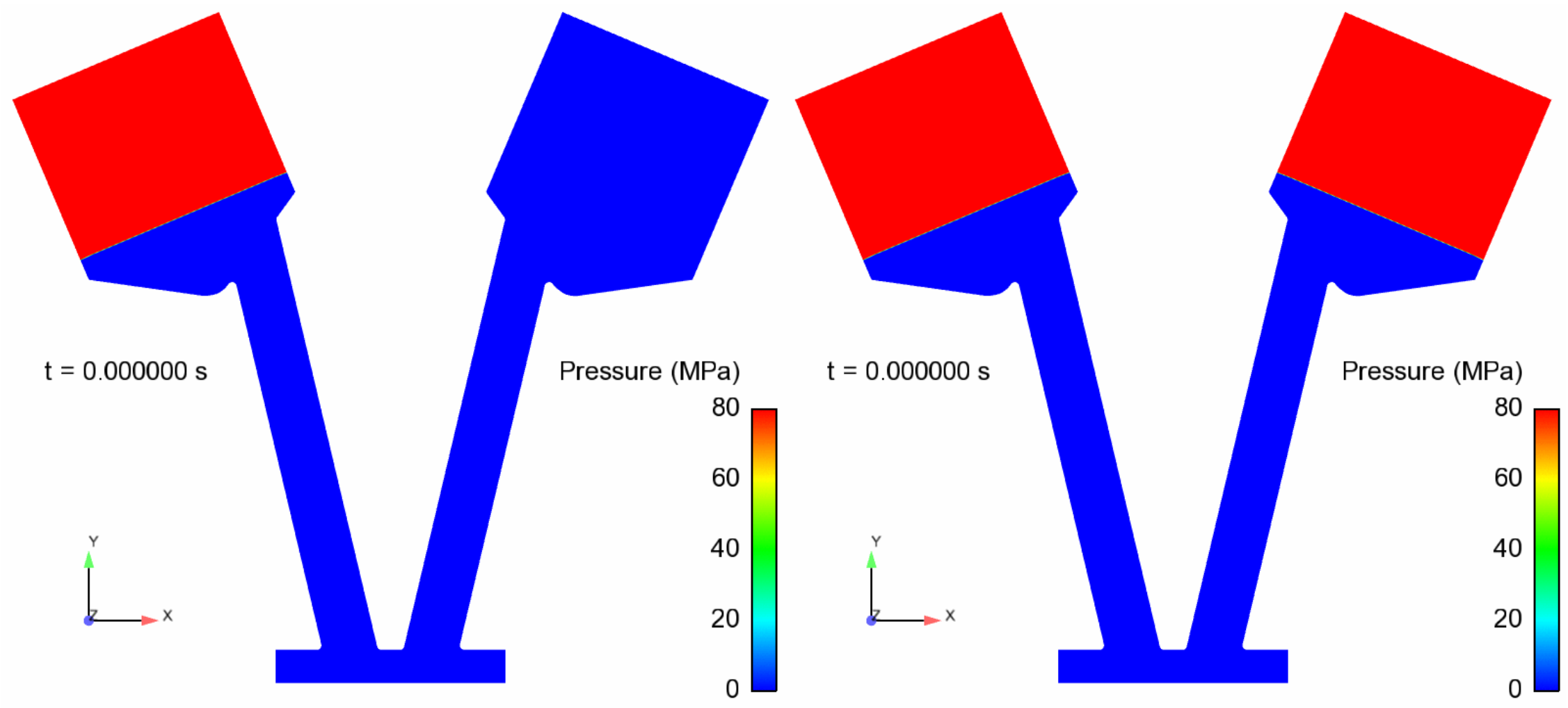


\section{2-D Planar Results: Mach Number Contours}

- As the pressure increases in the booster cap region, for the single firing case, the flow is relieved into the unused flow channel at a relatively high Mach number

- However, the dual firing case shows that the booster cap region is essentially a stagnation zone as the Mach number remains at zero

- This could reduce heat transfer significantly

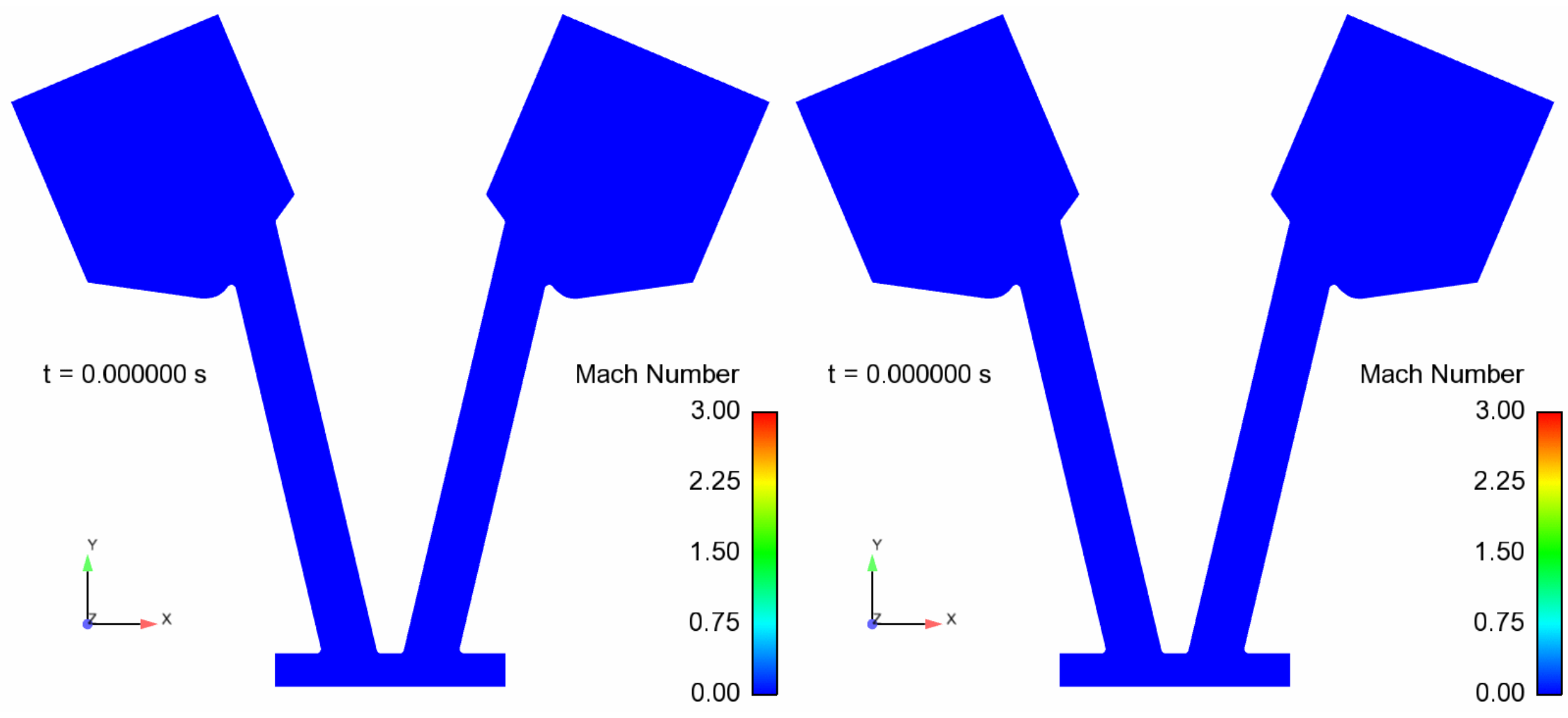




\section{2-D Planar Results: Temperature Contours}

- Temperature rise in booster cap region purely due to fluid compression from high pressure

- For single-firing case, shock wave reflection within the booster cap cavity moves the gas with significant Mach numbers

- For the dual-firing case, the flow stagnates inside the booster cap region

- Therefore, the heat transfer coefficient might be much lower for the dual firing case as compared to the hear transfer coefficient for the single-firing

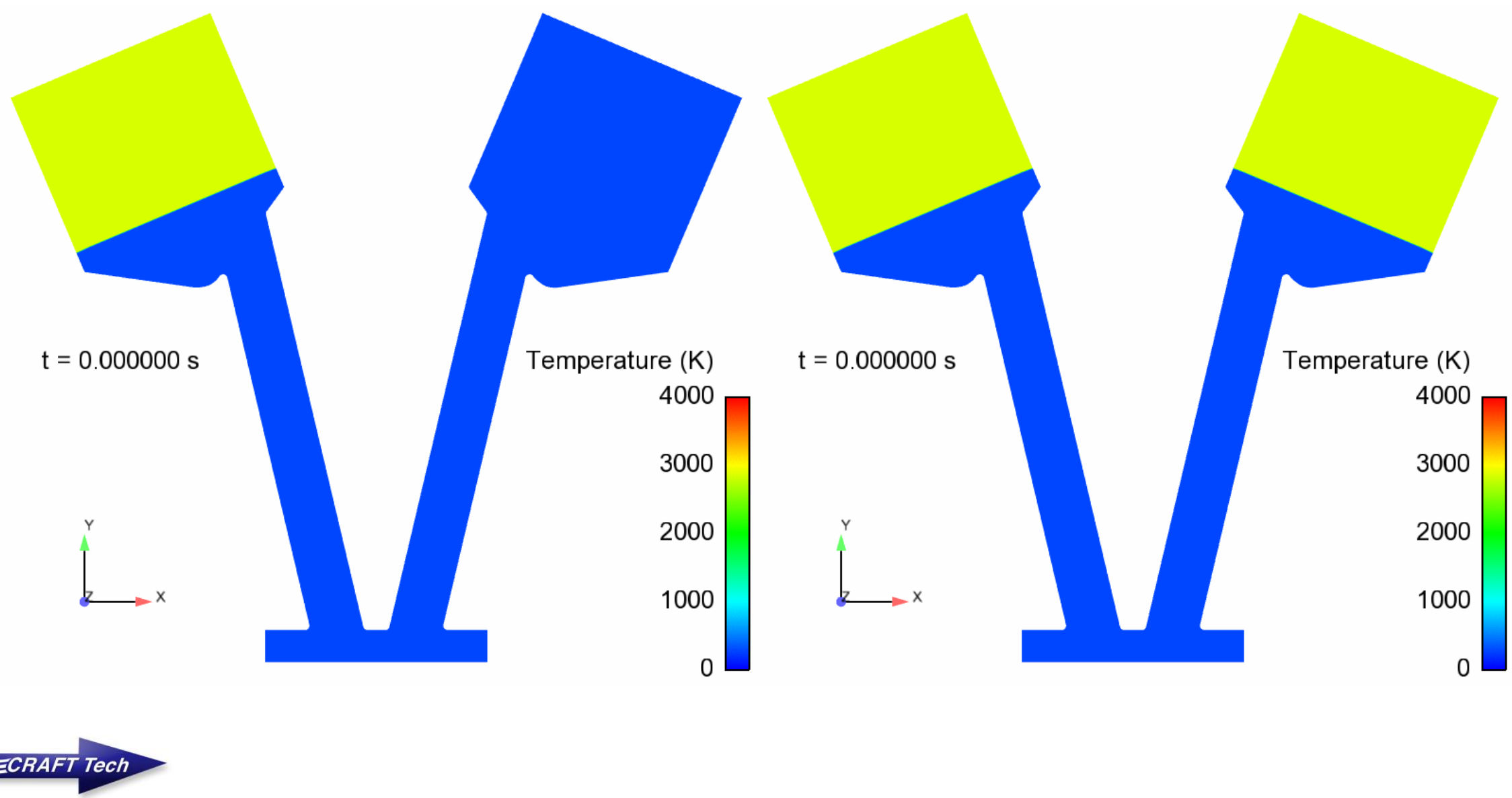




\section{2-D Planar Results: Solid Propellant Density Contours}

- The large pressure region at the end of the initiator zone caused the particles to enter the flow channels at an angle and travel along the inside walls

- The single firing case shows particles impacting the booster cap

- However, the dual firing case shows that due to the rapid pressure rise in the booster cap region and the associated backward flow, only a trace amount of particles are able to reach the booster cap

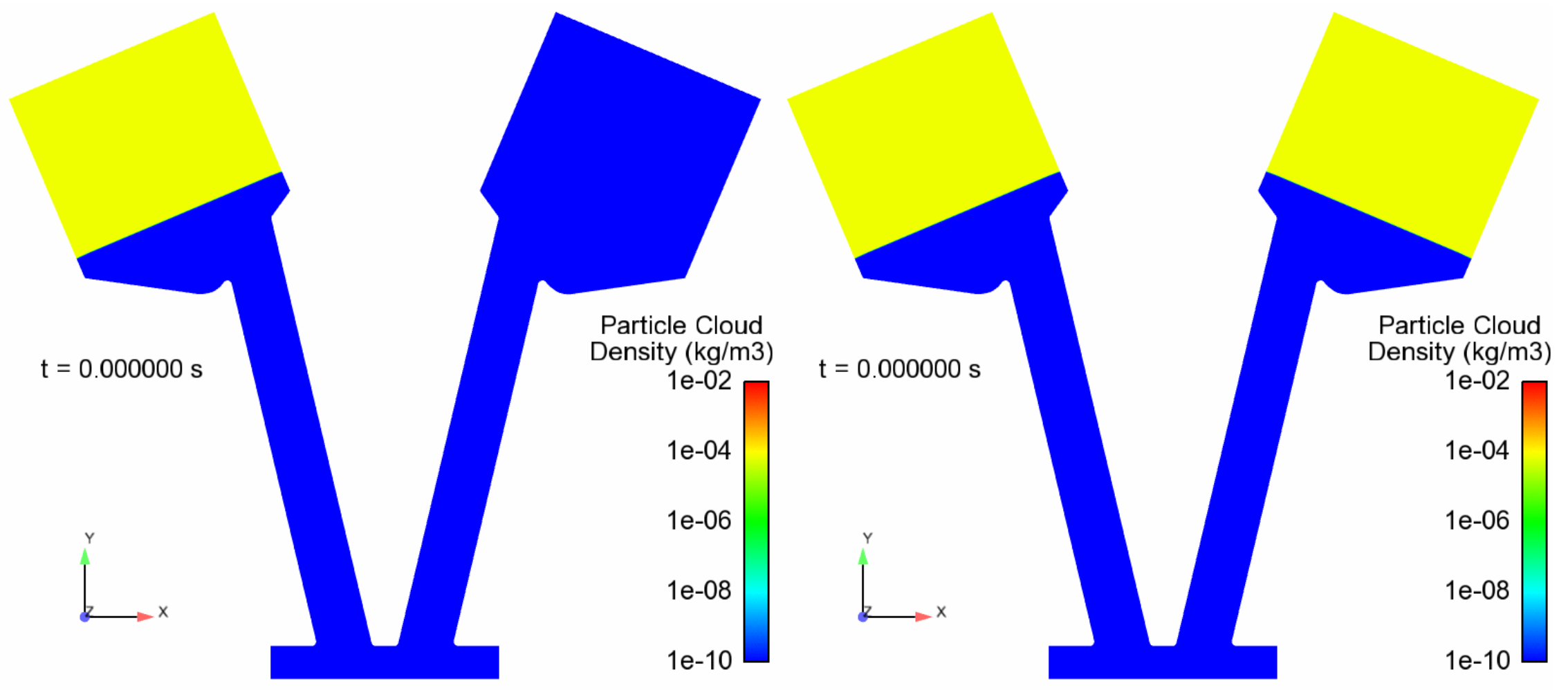




\section{3-D Planar Results: Pressure Contours}

- Animations of the pressure contours are shown on the symmetry plane and booster cap

- The pressure rise in the booster cap region for the simultaneous dual firing case reaches and sustains a much higher peak level than the single firing case

- In the single firing case, the pressure is relieved into the unused flow channel and charge area

- These predictions are similar to what was shown in the 2-D simulations

- The flow channels are offset in the radial direction from the end of the curved surface in the initiators

- This creates a large pressure rise which causes the flow to turn into the channel at an angle

- This turning has an implication on the path the particles take through the flow channel
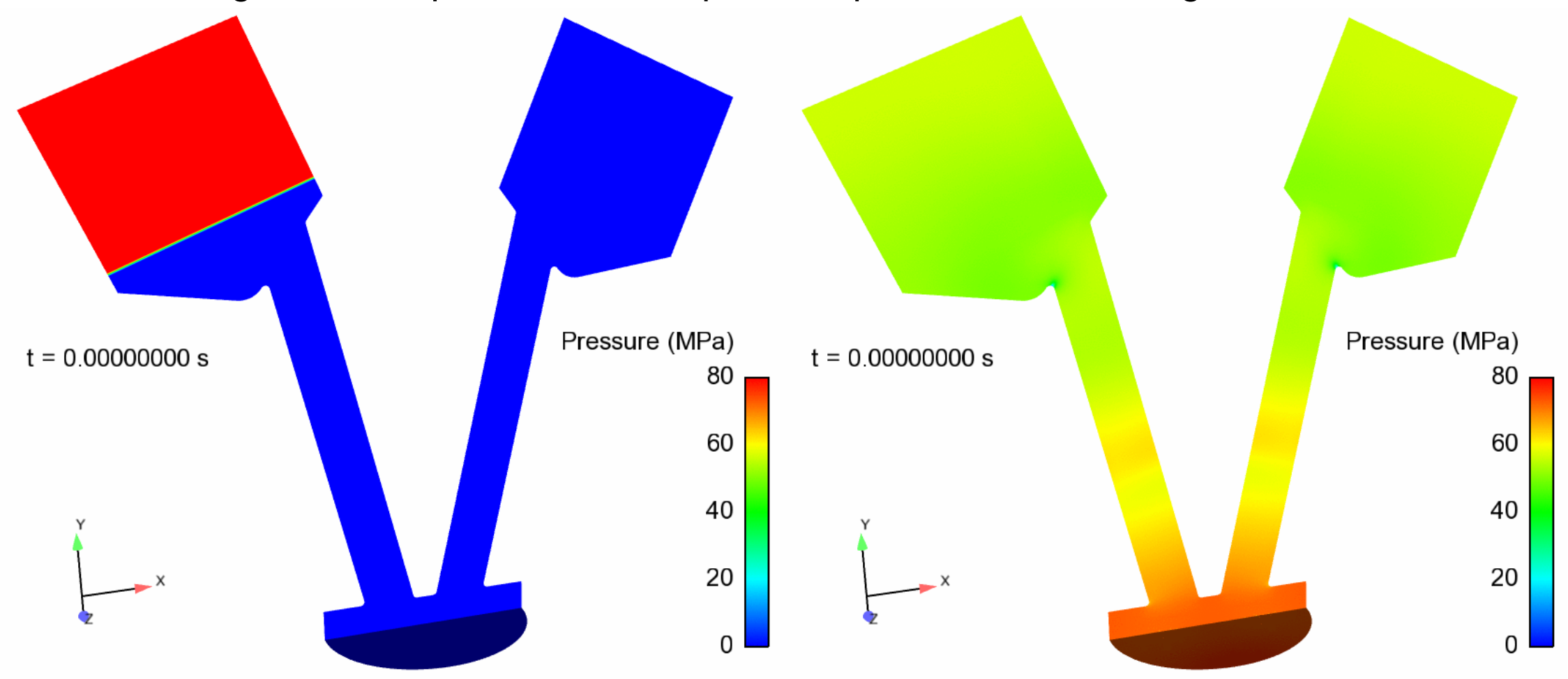


\section{3-D Planar Results: Mach Number Contours}

- As the pressure increases in the booster cap region, for the single firing case, the flow is relieved into the unused flow channel at a relatively high Mach number

- However, the dual firing case shows that the booster cap region is essentially a stagnation zone as the Mach number remains at zero

- Reverse flow into the flame channel occurs later in the cycle for the simultaneous dual firing case
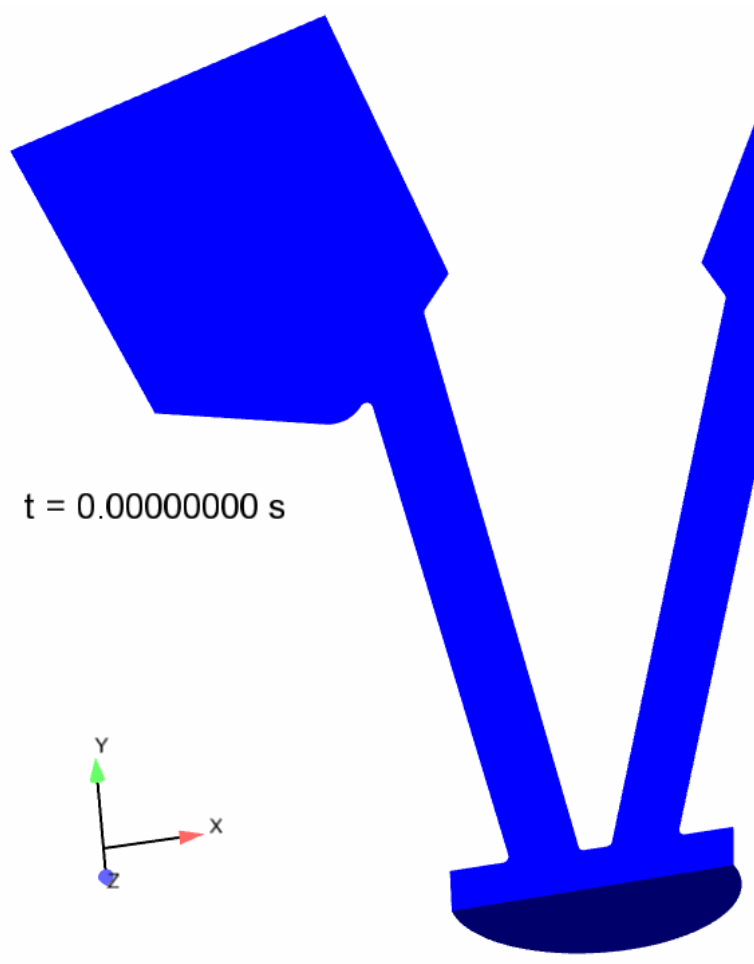

Mach Number
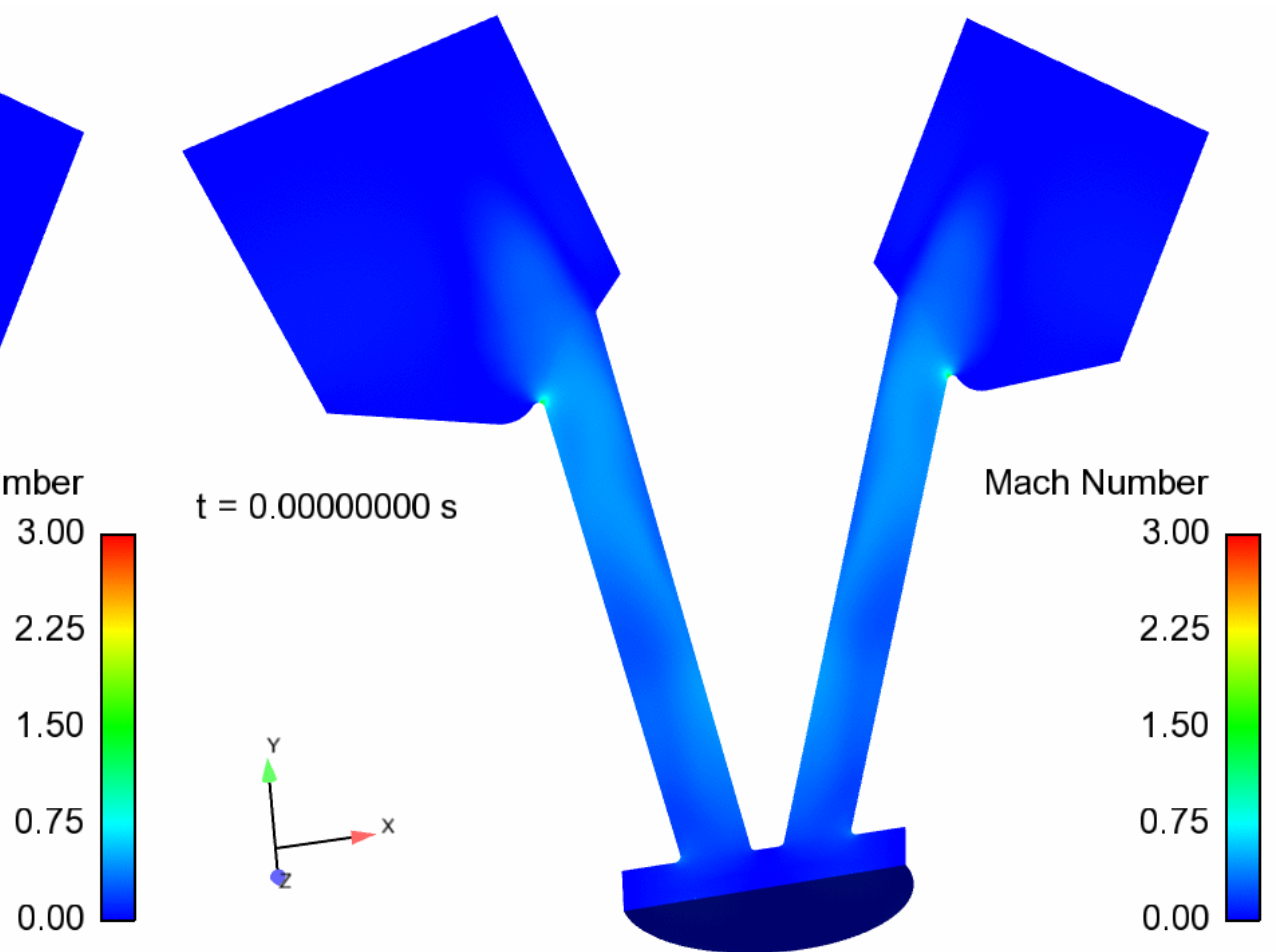


\section{3-D Planar Results: Temperature Contours}

- Temperature rise in booster cap region purely due to fluid compression from high pressure

- For single-firing case, shock wave reflection within the booster cap cavity moves the gas with significant Mach numbers

- For the dual-firing case, the flow stagnates inside the booster cap region

- Convective heat transfer in booster cap region has two competing effects:

- High pressure and temperature in dual firing case that increases quiescent heat transfer

- Stagnated flow that will reduce any convective effects that will be enhanced in the singlefiring case
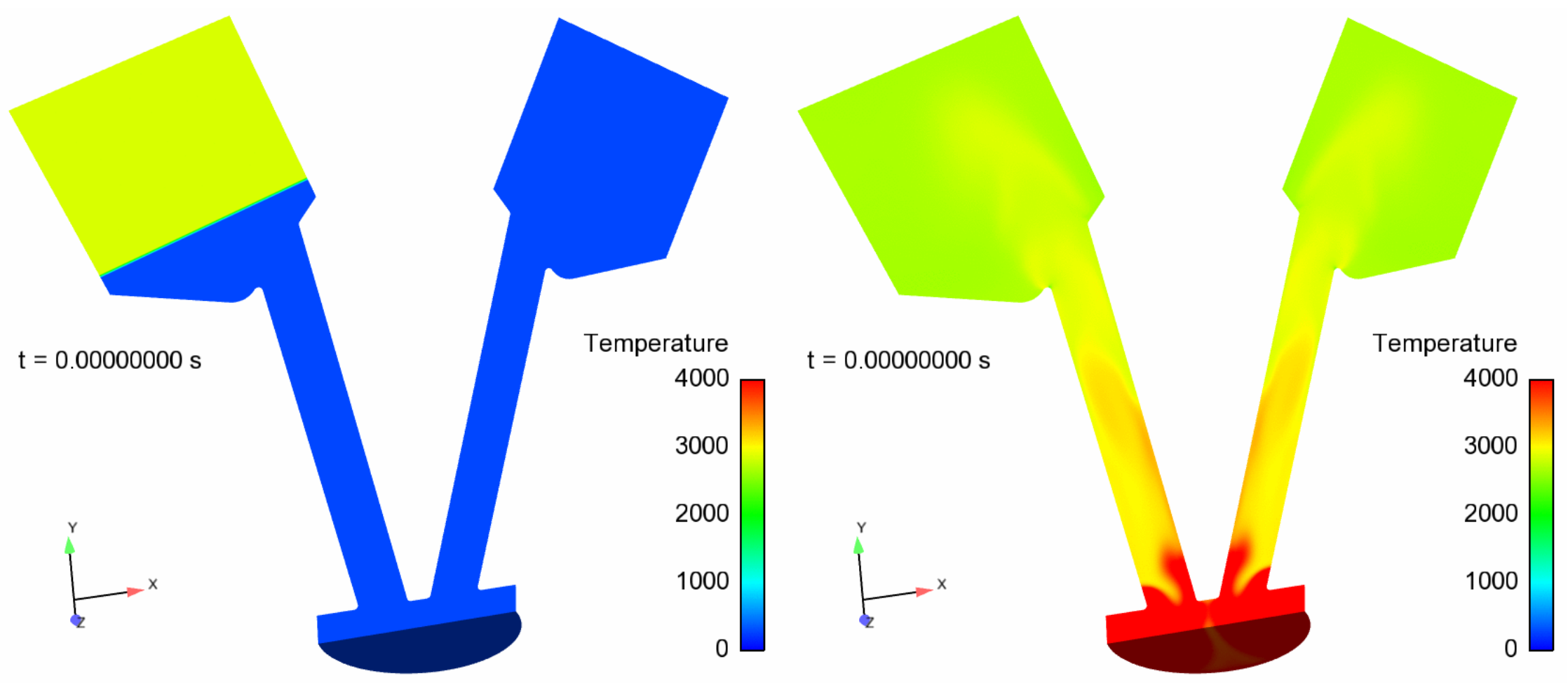


\section{3-D Planar Results: Solid Propellant Density Contours}

- Both dual and single firing cases show a significant amount of particles impacting the booster cap

- Accounting for the correct area/volume ratio in the 3-D configuration provides more relief than in the 2-D cases

- For the dual firing case, due to the high pressure stagnation in the booster cavity the particles begin to travel away from the booster cap after $\sim 35 \mu \mathrm{s}$

- For the single firing case, the particles from the active initiator continue to travel into the booster cavity and also into the unused initiator region

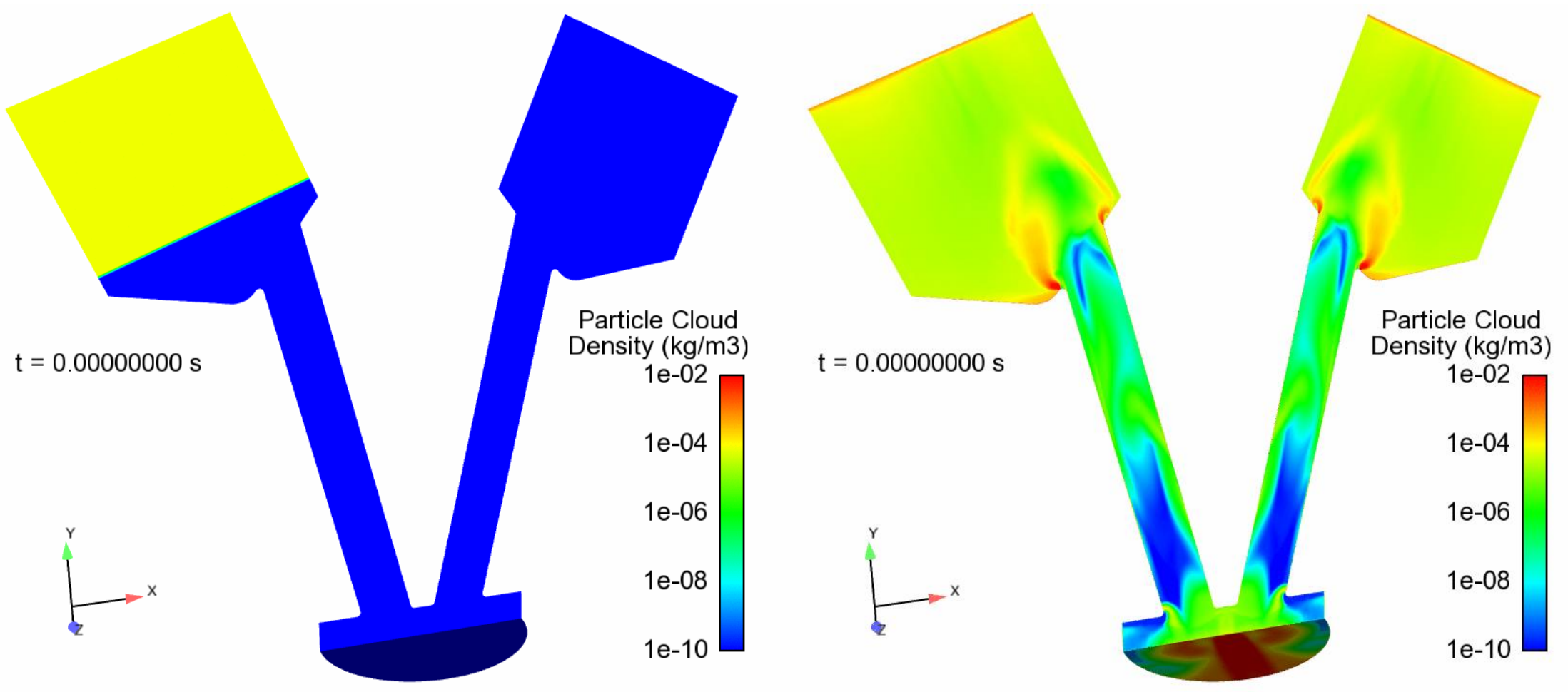




\section{3-D Results: Accumulation of Particles Near the Booster Cap}

- The mass of particles in a zone near the booster cap is plotted below

- Figure on left shows location of integration zone

- Figure on right shows the time-varying total mass of particles in the integration zone normalized by the mass of particles contained within a single initiator charge

- After $100 \mu \mathrm{s}$ the dual firing case shows half the amount of particles contained in the volume near the booster cap than the single firing case despite having twice the amount of particles

- Due to the flow reversal, much fewer particles are impacting the booster cap in dual firing case

- Fundamental hypothesis for failure of simultaneous dual-firing still valid
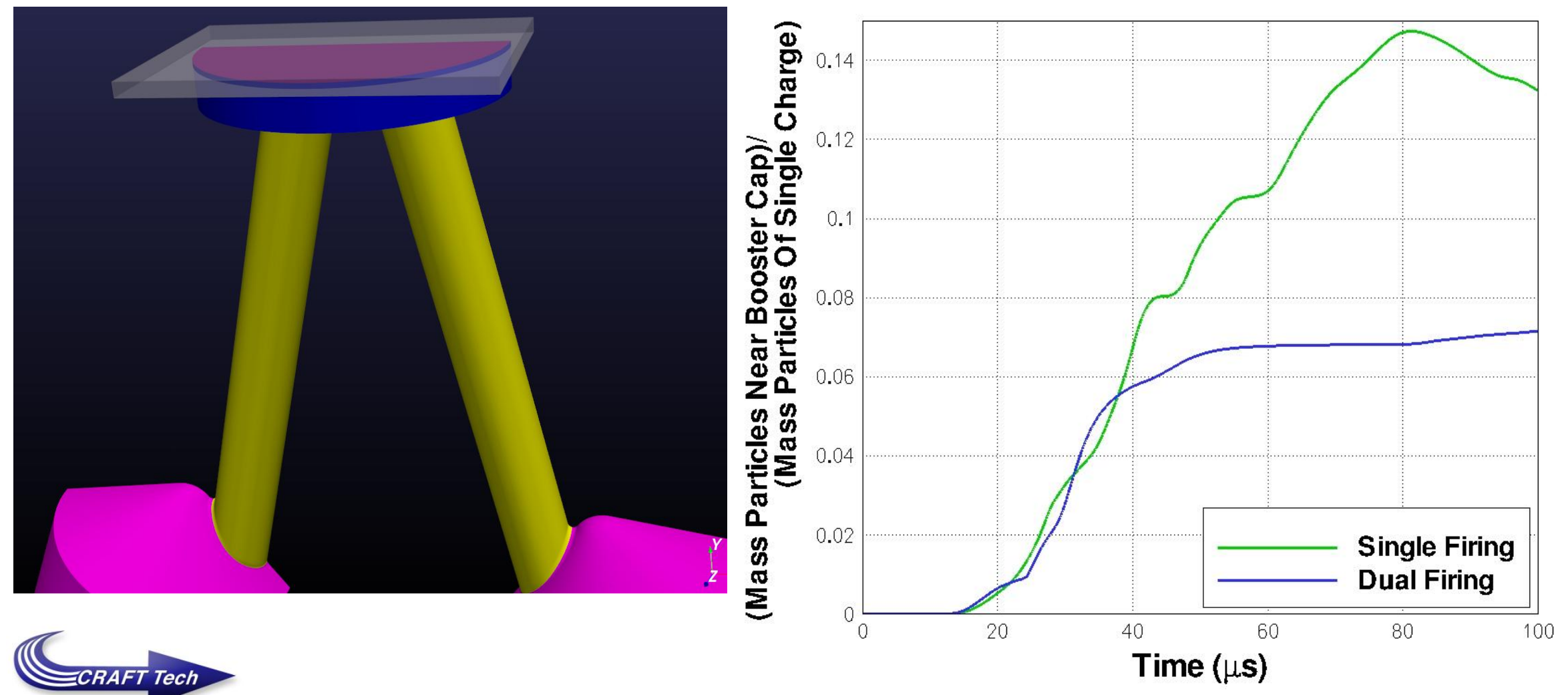


\section{3-D Results: Solid Propellant Particulate Impact Zones}

Particles travelling along inside wall could potentially lead to erosion of wall due to particle impact

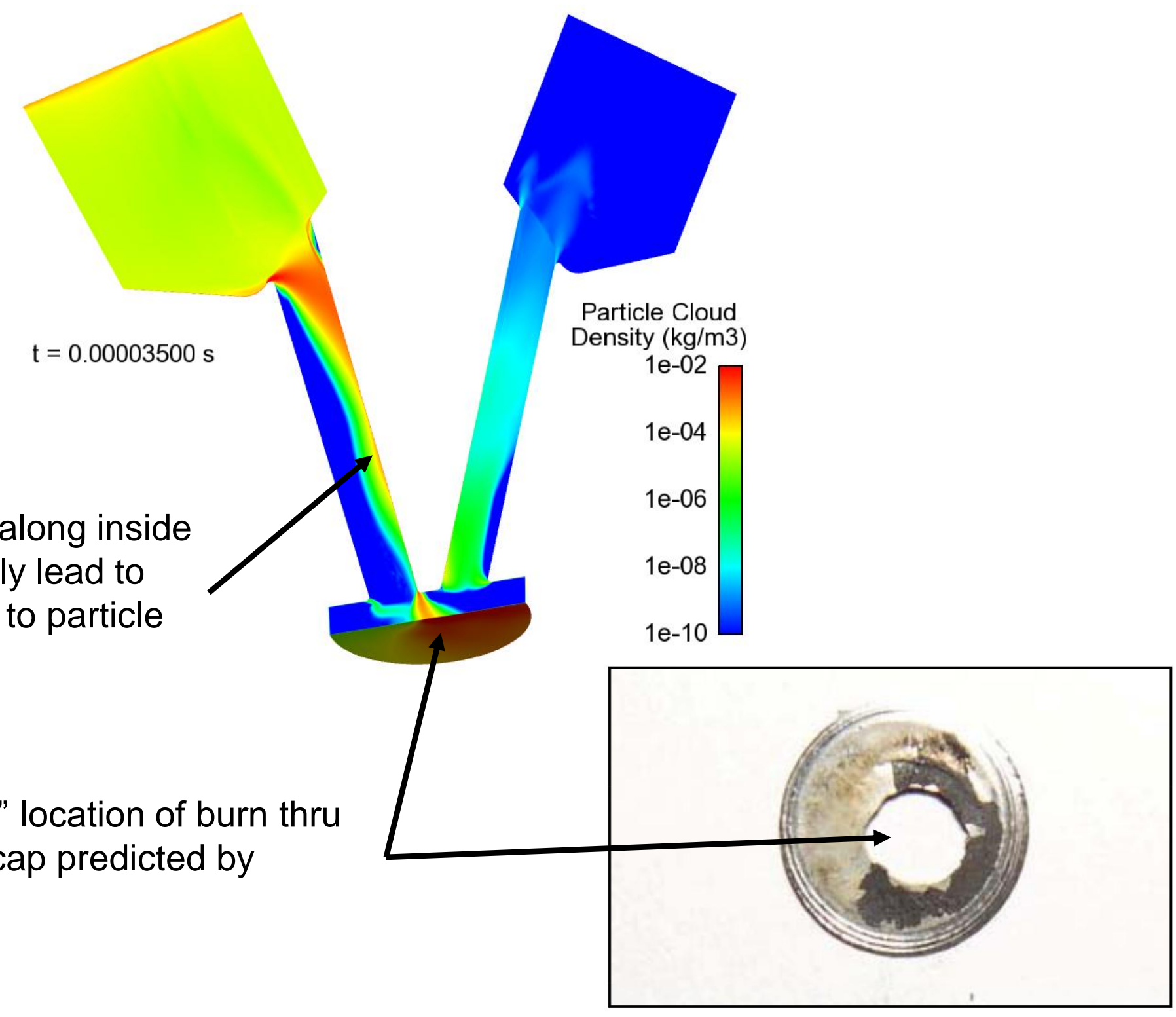

"Off-Center" location of burn thru of booster cap predicted by simulation 


\section{2-D Planar Heat Transfer Simulations}

- Fully coupled fluid and heat transfer simulations were performed for the single and simultaneous dual firings

- Schematic of stainless-steel casing shown below taken from IGES file

- Laminar and turbulent calculations were performed

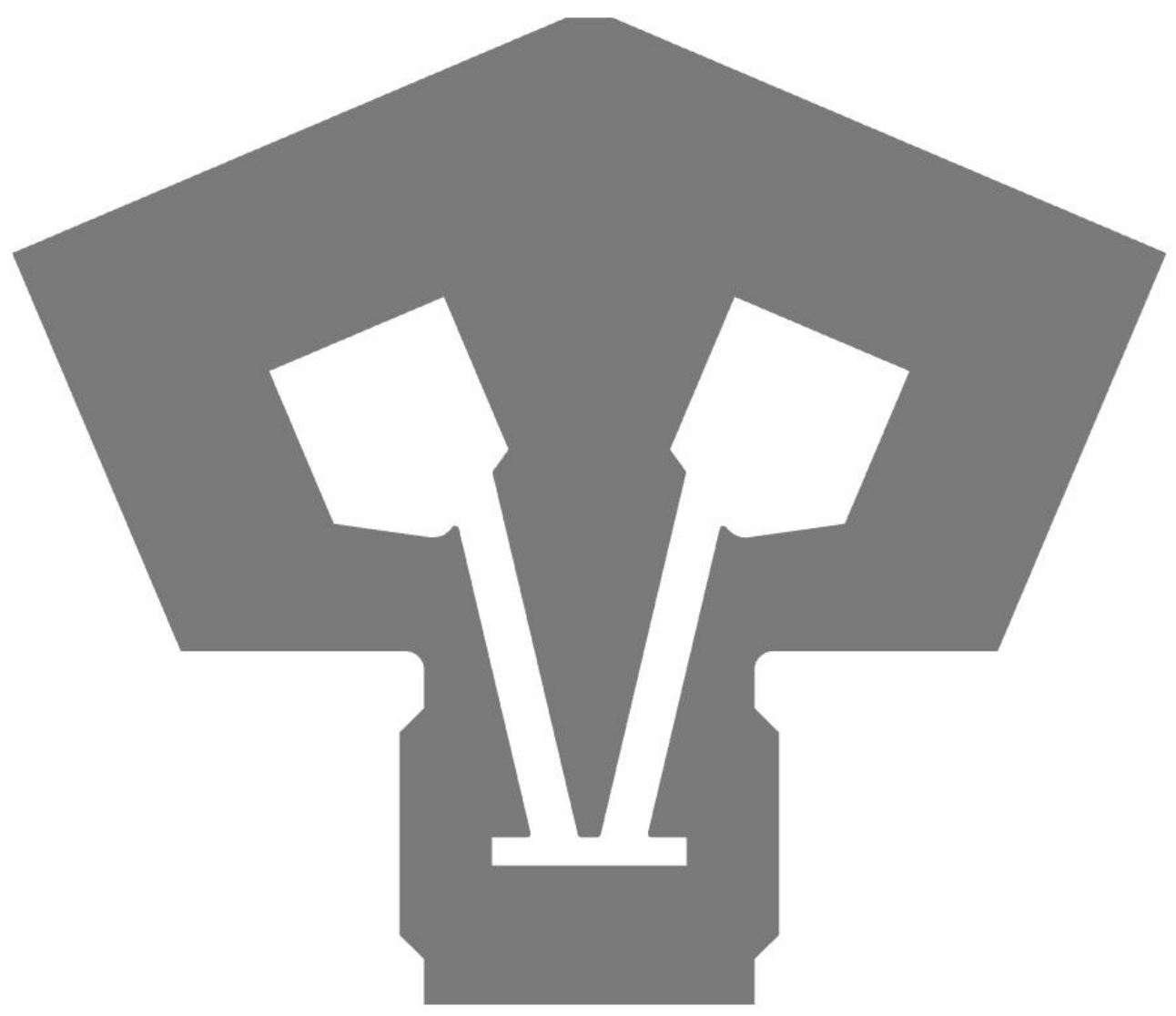




\section{2-D Planar Heat Transfer Simulations}

- Temperature contours in the casing material at $20 \mu \mathrm{s}$ for the simultaneous dual firing scenario

- Temperature has not increased substantially in the casing or conducted a far distance

- Contours for single firing scenario are very similar
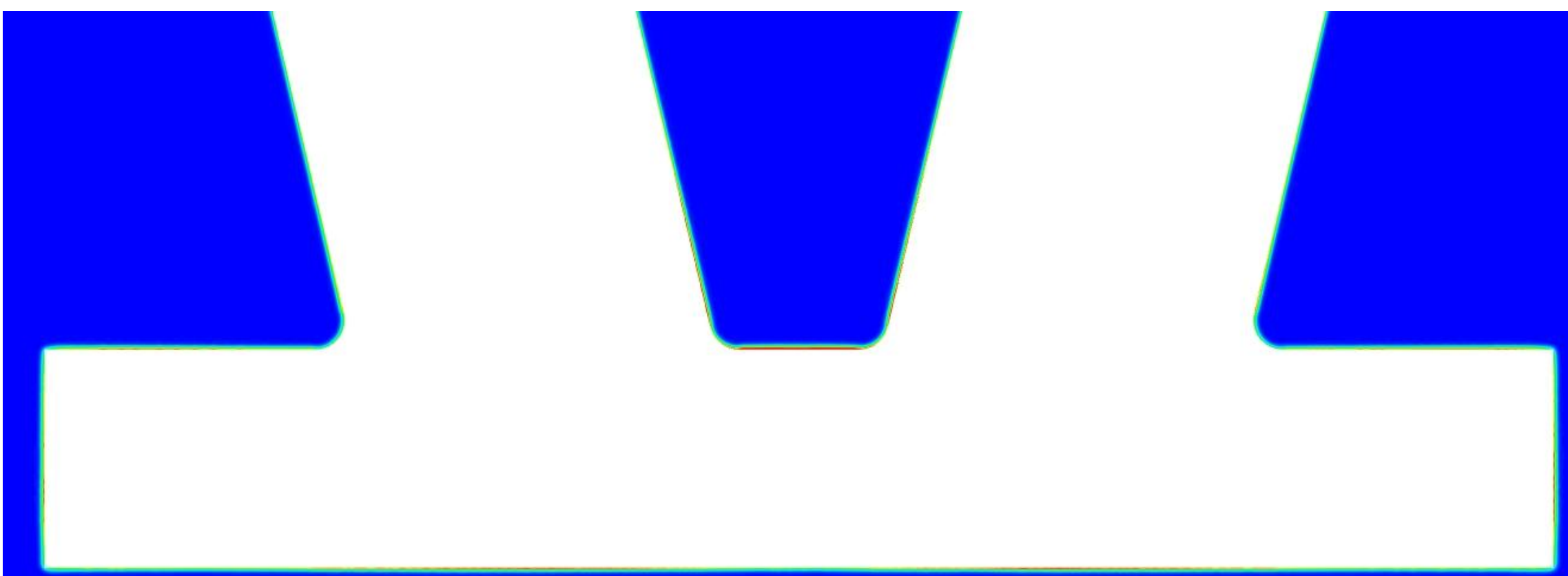


\section{Solid Temperature Profiles}

Temperature

profiles into the casing at the booster cap shown below at three different times
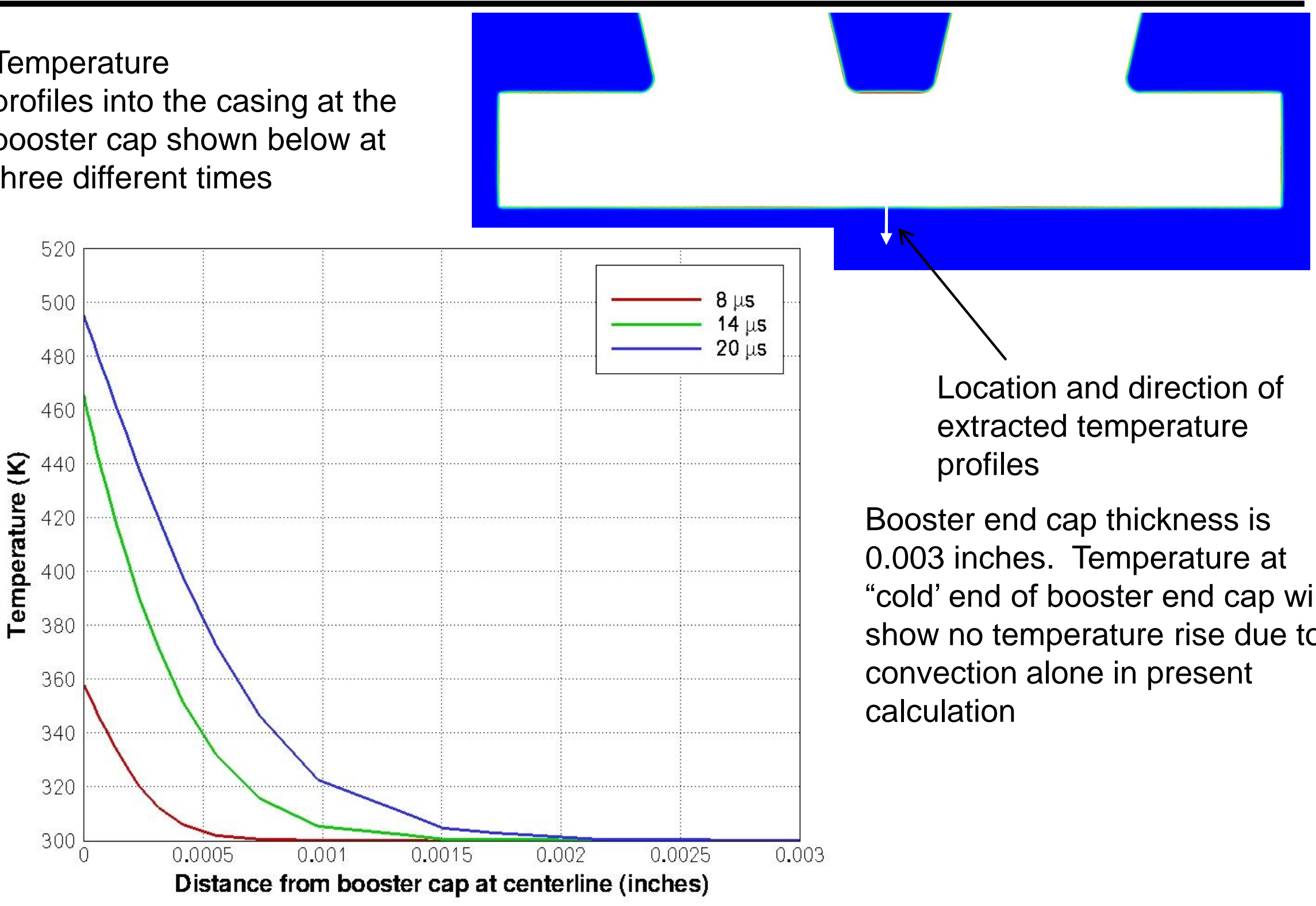

Booster end cap thickness is 0.003 inches. Temperature at "cold' end of booster end cap will show no temperature rise due to convection alone in present calculation 


\section{Heat Flux Predictions}

- Temperature, heat flux, and heat transfer coefficient plotted as a function of time for both firing scenarios on the booster capo for the turbulent calculations

- Heat transfer coefficient obtained as a postprocessing step

- Higher values for temperature and heat flux are found for the dual firing scenario

- Estimated heat transfer coefficients are essentially identical except for the higher single firing peak value

- A refinement study was conducted to ensure adequate resolution of the boundary layer for the fluid domain

- Require $y^{+}<1$ for heat transfer calculations
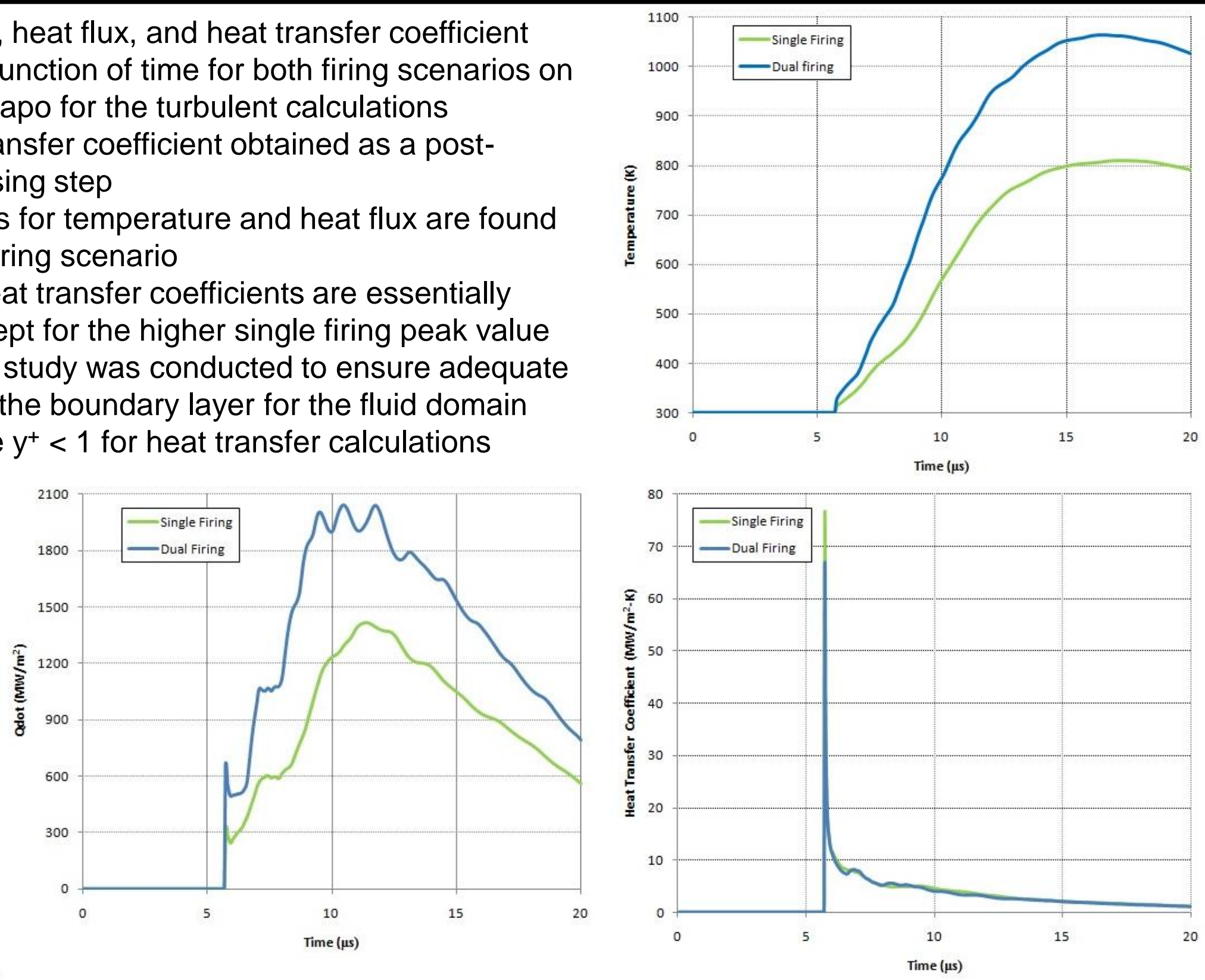


\section{Analytic Solution for a Semi-Infinite Solid}

The analytic solution for the temperature profile though a semi-infinite solid with a constant heat flux on the open end is given by:

$$
\begin{aligned}
T(x, t) & =T_{i}+\frac{2 q_{s} \sqrt{\alpha t / \pi}}{k} \exp \left(\frac{-x^{2}}{4 \alpha t}\right)-\frac{q_{s} x}{k} \operatorname{erfc}\left(\frac{x}{2 \sqrt{\alpha t}}\right) \\
T_{i}: & \text { Initial temperature }(\mathrm{K}) \\
q_{s}: & \text { Constant surface heat flux }\left(\mathrm{W} / \mathrm{m}^{2}\right) \\
k: & \text { Thermal conductivity }(\mathrm{W} / \mathrm{m} \cdot \mathrm{K}) \\
\alpha: & \text { Thermal diffusivity }\left(\mathrm{m}^{2} / \mathrm{s}\right)
\end{aligned}
$$

The computed temperature profiles can be compared against the analytical expression for varying constant surface heat flux values 


\section{Comparison of Temperature Profiles}

The computed temperature profiles shown in the upper right-hand figure for 8,14 , and $20 \mu \mathrm{s}$ are very similar to those determined from the analytic solution for constant surface heat fluxes of 400 and $800 \mathrm{MW} / \mathrm{m}^{2}$ shown below

Agreement between computational and analytical profiles give credibility to the numerical results
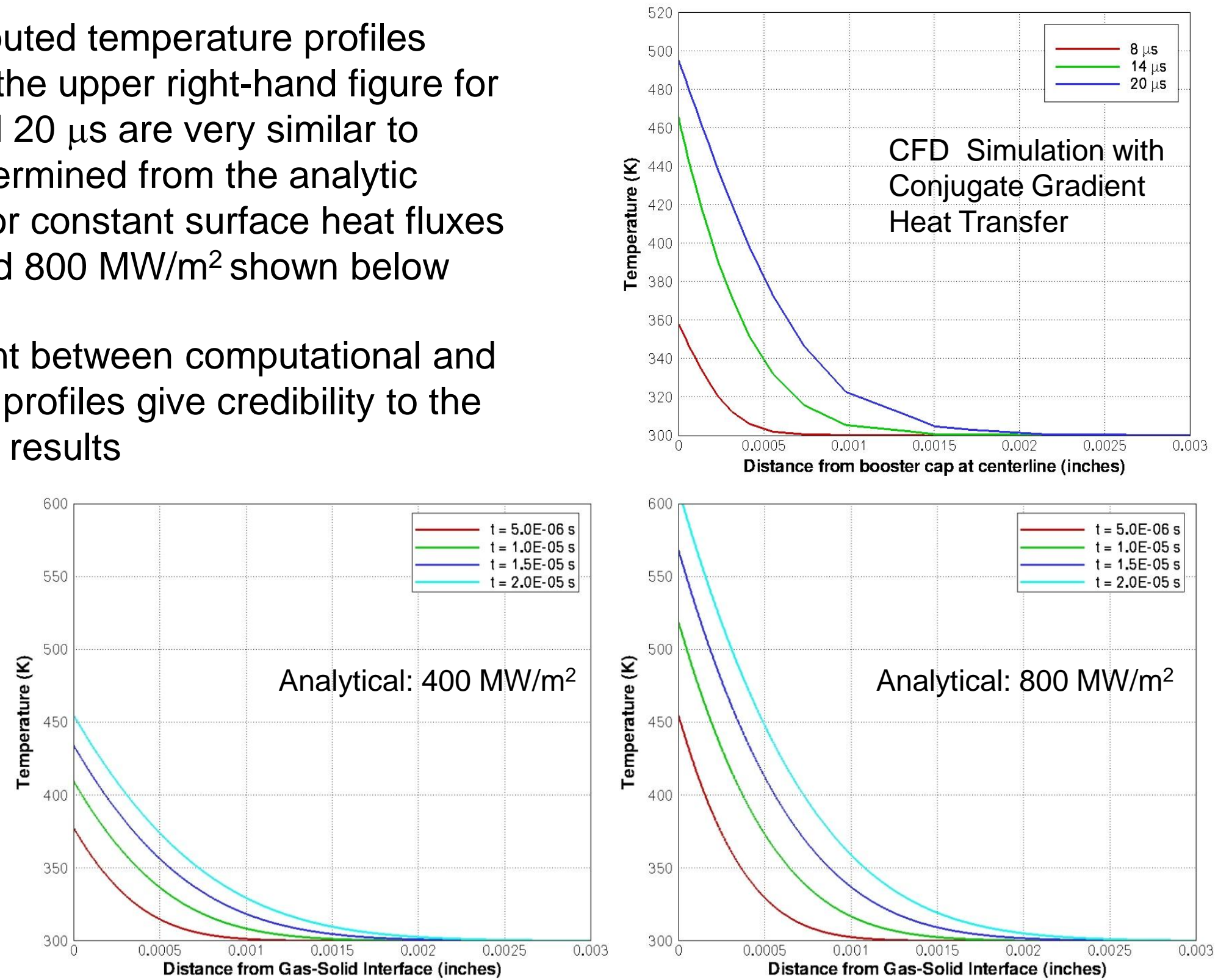


\section{Analytic Temperature Profiles}

A duration of approximately $800 \mu$ s is required for the temperature to exceed $1000 \mathrm{~K}$ at 0.003 inches away from the gas-solid interface when a constant heat flux of $600 \mathrm{MW} / \mathrm{m}^{2}$ is used

- The $800 \mathrm{~ms}$ duration is approximately the same time length from the experiments

- The analytic profiles indicate that the convective heat transfer could potentially account for substantial temperature rise as observed in the experiment

- Burn through of end-cap may be a combination of convective heating and particle impact onto the booster cap which will locally transfer

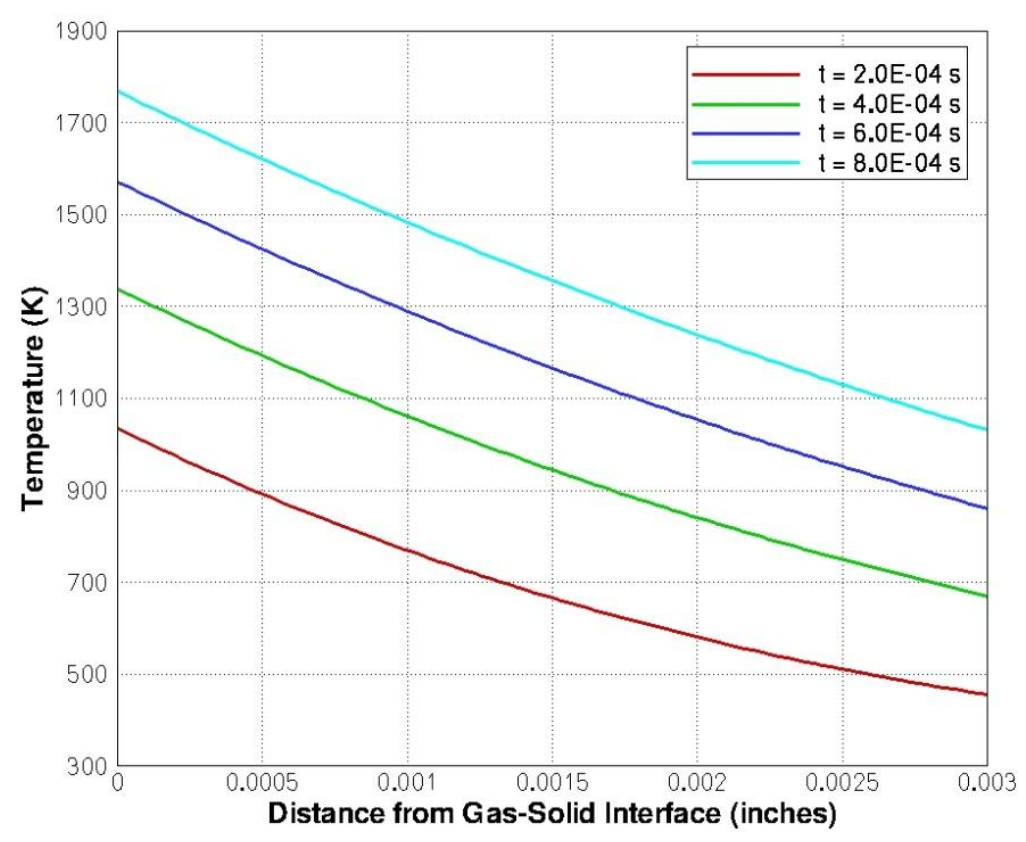
energy both due to its high momentum as well hot temperatures. This would potentially explain the difference between single and simultaneous dual firings

These results suggest that the mechanisms which cause the burn thru of the booster cap may not be fully understood and must be investigated further. It appears that the convective heat flux values predicted by CFD can potentially provide substantial temperature rise if maintained over an adequate time scale. 


\section{Concluding Remarks}

- For simultaneous dual-firing, the stagnation region formed in the booster cap cavity due to shock interaction caused reverse flow which impedes the particles from impacting the booster cap and reduces the convective heat transfer from the compressed gas

- In contrast, the unused initiator flow channel in the single firing case provides pressure relief; it allows for gas velocities to become supersonic and carry the particles along with them allowing them to impact the booster cap

- Preliminary heat transfer simulations indicate that convective heat transfer may be substantial but since time scales of present simulation are very low no definitive conclusions can be drawn on its relative importance

- Computational results show good agreement with the analytical solution for a semi-infinite solid with a constant heat flux

- The temperature rise may be limited by the short time-scales of simulation and insufficient energy addition due to charge initialization

- Future work will include:

- Refinement, improvement, and validation of the numerical framework

- Design support and characterization studies for the final PCA configuration 